\title{
pvSPS4 is Crucial for the Root Sugar Balance and Proper Tolerance Response in Salt-Tolerant Common Bean Genotype Under Salt Stress
}

Harun Niron ( $\square$ harunniron@gmail.com )

Bogazici University: Bogazici Universitesi https://orcid.org/0000-0001-5303-7024

Müge Türet

Bogazici University: Bogazici Universitesi

\section{Research Article}

Keywords: Salt stress, common bean, Sucrose phosphate synthase, tolerance, knock-down

Posted Date: February 11th, 2022

DOI: https://doi.org/10.21203/rs.3.rs-1302241/v1

License: (9) (i) This work is licensed under a Creative Commons Attribution 4.0 International License. Read Full License 


\section{Abstract}

Salinity is a stress factor that decreases global agricultural yield. Crops such as rice, tomato, potato, and legumes are susceptible to salt, thus this problem requires urgent attention. Stress-related carbohydrate metabolism is a dynamic network of genetic and metabolic pathways. Disruption in the regulation of soluble sugar content can have negative effects on source-sink partitioning. As source-sink partitioning is connected to the supply, and distribution of energy in the plant, it is critical for stress tolerance. Sucrose phosphate synthase (SPS) enzymes operate in a key regulatory step in sucrose synthesis. Therefore, they have a significant role in sugar metabolism including the regulation of source-sink sucrose transportation. This study focused on the function of the SPS homolog -pvSPS4-in the roots of legume crop common bean under salinity stress. We previously showed that pVSPS4 expression is root-specific and is upregulated under salt stress in a salt tolerant common bean genotype. This upregulation was accompanied by an accumulation of sugars in the roots. In the current study, using the same genotype, we generated composite common bean plants with wild-type shoot and pvSPS4 knock-down roots. Composite plants exhibited increased sensitivity to salt stress compared to control and mock plants. pvSPS4 knock-down disturbed the root glucose/sucrose ratio and ionic balance which resulted in a reduction in photosynthetic pigments together with osmoregulation and antioxidant capability. Our results imply that pvSPS4 is an important gene for carbohydrate balance regulation as a salt-stress response in the common bean root tissues.

\section{Key Message}

Knock-down of sucrose metabolism gene sucrose phosphate synthase-4 in salt-tolerant common bean roots disrupts salt tolerance mechanisms through generation of sugar and ion imbalance under salt stress.

\section{Introduction}

Soil salinity is one of the world's most widespread and detrimental agricultural problems. Projections show that more than $20 \%$ of farmlands are affected by over-salinization globally (Munns and Tester 2008). This percentage is expected to increase annually due to improper irrigation, disproportionate evaporation, or insufficient precipitation and reach 50\% by 2050 (Jamil et al. 2011). Major crops such as maize, potato, rice, tomato, and legumes are susceptible to salinity-related yield loss, thus this issue requires urgent attention (Muchate et al. 2016).

Stress-associated sugar metabolism is a dynamic process that is interconnected with numerous other metabolic and genetic pathways. Variations in $\mathrm{CO}_{2}$ fixation can cause fluctuations in soluble carbohydrate content and interrupt the source-to-sink carbon partitioning. Regulation of such impairments requires the expressional adjustment of many genes and proteins (Roitsch 1999; Gupta and Kaur 2005). As source-sink partitioning is directly connected to energy and resource allocation throughout the plant, it is a crucial factor in stress tolerance (Ho 1988; Krapp and Stitt 1995). Additionally, soluble sugars act as primary messengers and take a role in the regulation of growth and development-related genes, thus disruption of carbon partitioning results in extensive complications when plants are under stress (Coruzzi and Bush 2001; Rolland et al. 2006; Chen 2007).

Common bean (Phaseolus vulgaris L.) is a salt-susceptible major legume crop that can suffer around $20 \%$ loss in yield even at low salinity levels (Chinnusamy et al. 2005). Since it represents nearly half of global legume production, such a drop in yield can lead to problems with the nutrition of a high percentage of the human population (Broughton et al. 2003).

Our previous omics study compared two common bean genotypes to understand the divergence in their salt-tolerance responses. This revealed a major distinction in carbohydrate metabolism between these genotypes: The tolerant genotype Ispir accumulated greater levels of soluble carbohydrates in the roots compared to the susceptible genotype (TR43477). Together with this accumulation, a sucrose phosphate synthase (SPS) gene displayed a sharp upregulation in expression in the tolerant genotype that is absent in the susceptible genotype (Niron et al. 2020).

SPS enzymes act in the first step of the sucrose synthesis pathway with the transfer of a glycosyl group from an activated sugar donor such as uridine diphosphate glucose to an acceptor fructose-6'-phosphate to generate sucrose-6'-phosphate (Chua et al. 2008). As a rate-limiting step, this reaction constitutes a crucial regulatory phase for the synthesis of sucrose (Stitt et al. 1988; 
Huber and Huber 1996). Therefore, SPS enzymes have a key role in carbohydrate metabolism with the adjustment of partitioning among starch production and soluble sugar accumulation in several physiological systems (Geigenberger et al. 1999; Lunn and MacRae 2003; Baxter et al. 2003; Chen et al. 2005). Furthermore, they are tightly connected with the level of source-to-sink sucrose translocation (Huber and Huber 1992) and since nearly $80 \%$ of fixed carbon is exported to sink tissues (Kalt-Torres and Huber 1987), SPS regulation of partitioning is critical for control growth and development (Gifford et al. 1984).

There are multiple SPS homologs in plant species, and their transcriptional regulation depends on developmental stage, tissue type, and environmental stimuli (Reimholz et al. 1997; Lunn 2003; Lutfiyya et al. 2007). SPS activity may display an increase or decrease in response to salinity stress depending on the genotype or species (Amirjani 2010; Peng et al. 2016). Similarly, SPS activity was demonstrated to increase in drought-stressed wheat (Fresneau et al. 2007), and rice leaves (Xu et al. 2015), yet a recent study of soybean under drought stress showed increasing and decreasing patterns of expression depending on developmental stage, tissue type, and SPS homolog (Du et al. 2020). Another recent study on cold-stressed maize plants also demonstrated the genotype effect on SPS regulation (Bilska-Kos et al. 2020). The range of variability in SPS expression and protein activity indicates a comprehensive regulatory function for this enzyme family, thus further attention is necessary to enhance our knowledge of the role of SPS enzymes not only in plant metabolism but also in stress tolerance.

There is a large body of research on the role of SPS genes in photosynthetic tissues, hence much of the knowledge of its function and regulation is related to these tissues (Huber and Huber 1996; Lunn and MacRae 2003; Baxter et al. 2003). On the other hand, the function of SPS enzymes in non-photosynthetic tissues, where sucrose is imported and degraded, is not yet clear. SPS may have two roles in non-photosynthetic tissues: It may take part in sucrose re-synthesis subsequent to import through apoplastic cleavage or it may be directly involved in the sugar regulatory cycle with the organization of sucrose and/or starch balance (Geigenberger et al. 1999).

In this study, we have generated composite common bean plants with Ispir genotype (salt-tolerant), through Agrobacterium rhizogenes mediated transformation, that have SPS4 (pvSPS4) knock-down roots and wild-type shoots to understand the role of a root-specific, salt stress-responsive SPS enzyme in salt stress tolerance. Root pvSPS4 knock-down disturbed the glucose/sucrose ratio in root tissues which caused ionic imbalance and reduced carbon fixation. Knock-down plants displayed reduced growth, higher cell death, and decreased osmoprotection and antioxidant capacity. Here we report that pvSPS4, through the regulation of sugar balance, acts as a crucial salt-stress response actor in the root tissues of common bean.

\section{Methods}

\section{Bacterial strain, plasmid, and vector construction}

Part of the human ferritin (EC:1.16.3.1) gene was selected to be cloned as a mock control, to invoke the RNAi system in common bean roots in a nonselective manner. 280bp and 268bp fragments for common bean pvSPS4 (Phvul.005G002600) and human ferritin genes respectively were amplified (Table 1) to be inserted into the pK7GWIWG2_II-RedRoot RNAi Gateway vector. The vector consists of an intron-linker between insertions to produce an intron-containing hairpin RNA (ihpRNA) for the use of host RNAi machinery together with a dsRED reporter linked to a 35 S promoter. Obtained expression vectors were transformed to $A$. rhizogenes $\mathrm{K} 599$ strain.

\section{Composite plant production, plant growth, stress treatment}

Three separate lines of composite plants with wild-type shoots and transgenic hairy-roots were created for comparative analysis: Blank, mock and pvSPS4 knock-down. Blank plants had hairy roots without any construct; mock plants (HumFer thereafter) had hairy roots with human ferritin-ihpRNA construct and plants with pvSPS4-ihpRNA construct carrying hairy-roots (SucPho thereafter). Five independent (from separately transformed individual common bean plants) composite plants were generated and grown as biological replicates for each line and condition. 
Production of transgenic hairy-roots on common bean (Ispir genotype) plantlets was performed as described by EstradaNavarrete et al. (2007) with minor modifications. Surface sterilized seeds ( $96 \%$ ethanol - $5 \%$ hypochlorite) were germinated on UV sterilized petri dishes with $\mathrm{ddH}_{2} \mathrm{O}$ soaked - autoclaved napkins at $24^{\circ} \mathrm{C}$ for 2 days. Seedlings were transferred to vermiculite-pots saturated with half-strength $\mathrm{B} \& \mathrm{D}$ (Mix $0.5 \mathrm{ml}$ per liter of each stock solution: $1 \mathrm{M} \mathrm{KH}_{2} \mathrm{PO}_{4} \mathrm{pH} 7.0,2 \mathrm{M} \mathrm{CaCl}, 20 \mathrm{mM}$ Fe-citrate and minimal stock $\left(0.5 \mathrm{M} \mathrm{MgSO}_{4}, 0.5 \mathrm{M} \mathrm{K}_{2} \mathrm{SO}_{4}, 2 \mathrm{mM} \mathrm{MnCl}_{4} 4 \mathrm{mM} \mathrm{H}_{3} \mathrm{BO}_{3}, 1 \mathrm{mM} \mathrm{ZnSO}_{4}, 4 \mathrm{mM} \mathrm{CuSO}_{4}, 0.2 \mathrm{mM} \mathrm{CoSO}, 0.2 \mathrm{mM} \mathrm{Na}_{2} \mathrm{MoO}_{4}\right)$.) solution (supplemented with $4 \mathrm{mM} \mathrm{KNO}_{3}$ ) and grown for about 5 days until the emergence of cotyledons. At this point, the pods were soaked with full-strength $\mathrm{B} \& \mathrm{D}$ (supplemented with $8 \mathrm{mM} \mathrm{KNO}_{3}$ ) and hairy-root transformation for the selected genes was performed. For the growth of hairy roots, the pods were transferred to transparent containers that ensured a humidity level above $95 \%$. The leaves were sprayed with $\mathrm{B} \& \mathrm{D}$ (supplemented with $8 \mathrm{mM} \mathrm{NO}_{3}$ ) every two to three days to keep the humidity levels high. After 18-21 days post-transformation, primary roots were removed by excision approximately one $\mathrm{cm}$ below the hairy root emergence site. Plants with transgenic hairy roots were transferred to bigger (12cm diameter) pots with B\&D (supplemented $8 \mathrm{mM} \mathrm{KNO}_{3}$ ) saturated vermiculite, the leaves were sprayed, and the plants were grown in transparent containers for another week to facilitate root growth, before removing the lid of the containers. Plants were irrigated with half-strength B\&D (supplemented with $2 \mathrm{mM} \mathrm{KNO}_{3}$ ) and grown for another week. After this point, control plants were grown in optimal conditions. Salt treatment was performed in line with our previous study to obtain compatible results: The plants were subjected to gradual $\mathrm{NaCl}$ treatment starting with $50 \mathrm{mM}$ first day, increased to $100 \mathrm{mM}$ on the second day, and set to $125 \mathrm{mM}$ on the third day. In total, the plants were grown under $125 \mathrm{mM} \mathrm{NaCl}$ for three days before they were sacrificed for tissue sample collection.

The employed methodology for composite plant generation introduced stress factors before salt application: Excision of primary root and high levels of humidity. As a result, most of the cotyledons fell off or in a necrotic phase before the start of salt treatment, therefore they were not used as samples in this study. Five plants were grown as biological replicates for each line and condition.

\section{Measurement of gene expression and protein levels}

Total RNA extractions for RT-qPCR analysis were performed with $0.1 \mathrm{~g}$ homogenized root tissue, using Tri Reagent@ (Sigma, US) according to the manufacturer's instructions. Quantification and quality of the RNA samples was determined both spectrophotometrically (Barbas et al. 2007) and using 1\% denaturing agarose gel electrophoresis. RT-qPCR was carried out with primers for pvSPS4 and its two close homologs, pvSPS1 and pvSPS3 (Table 1) with 10ng of cDNA from the hairy roots. Three biological replicates with experimental triplicates were used for analysis. PikoReal 96 Real-time PCR system (Thermo Fisher Scientific, DE) was utilized for the experiment. Actin-11 (GenBank: CV529679.1) was used as the reference gene. Relative expression levels were calculated by $2^{\Delta \Delta} \mathrm{Ct}$ method (Livak and Schmittgen 2001).

Root crude extracts to be used in Elisa and Western-blotting (WB) experiments were prepared by mixing $0.1 \mathrm{~g}$ ground root tissue with pH 7.8 100mM PBS (with Roche cOmplete ${ }^{\mathrm{TM}}$ Proteinase Inhibitor and 0.1mM EDTA) and collecting the supernatants. Protein concentrations of samples were measured with Pierce ${ }^{T M}$ BCA Protein Assay Kit (Thermo Scientific, US).

WB was performed with $25 \mu \mathrm{g}$ of protein. Proteins were separated with SDS-PAGE (10\% polyacrylamide) and transferred into a PVDF membrane. The membrane was incubated in blocking solution (4\% skimmed milk dissolved in TBS-T) for 1 hour at room temperature and then incubated in primary antibody (Anti-SPSC AS152997 or Anti-Actin AS132640 - Agrisera, SE) solution at $4^{\circ} \mathrm{C}$ overnight. The next day, the membranes were washed three times with TBS-T and incubated in secondary antibody of goat anti-rabbit IgG HRP conjugate (sc-2004 - Santa Cruz Biotechnology, US) solution for 1 hour at room temperature before visualization using luminol working solution (ECL, Bio-Rad, US) with GBOX F3 gel documentation system (Syngene, US). The relative band intensities were measured with ImageJ software (Schneider et al. 2012).

The enzyme-linked immunosorbent assay (Elisa) for the measurement of Phvul.003G170100 (Putative SPS1A) levels was performed with 750ug protein using Plant Sucrose Phosphate Synthase SPS ELISA Kit (MBS269987, MyBioSource, US) according to manufacturer's instructions. The standard SPS sample of the kit (Solanum tuberosum SPS1A UniProtKB_Q43845) was also used in WB experiments as the negative control. 


\section{Glucose and sucrose measurement}

Root soluble carbohydrates were extracted with $96 \%$ ethanol as described by Maness (2010)(Maness 2010) with 0.1g ground root tissue. The vacuum dried extracts were extracted in $150 \mu \mathrm{d} \mathrm{H}_{2} \mathrm{O}$ for further analysis. The colorimetric measurement of glucose and sucrose contents was performed with Glucose and Sucrose Assay Kit (MBS841570, Mybiosource, US) using 10 $\mu$ l of sample.

\section{Physiological parameters}

Leaf area quantification was performed manually with ImageJ software (Schneider et al., 2012) using three leaves from each plant. Fresh, turgor, and dry weight measurements were performed for five $1.5 \mathrm{~cm}$ diameter leaf discs and relative water contents (RWC) were calculated using the formula given below: (Barrs and Weatherley 1962). Leaf discs were incubated in $\mathrm{ddd}_{2} \mathrm{O}$ for $4 \mathrm{~h}$ for the determination of turgor weights. Dry weight measurements were taken following overnight incubation in $80^{\circ} \mathrm{C}$ oven.

Electrolyte leakage assay was performed with five $1.0 \mathrm{~cm}$ diameter leaf sections. Increase in the electrical conductivity of the water was measured with a conductivity meter at 2nd, 4th, and 8th hours after sectioning (Hatsugai and Katagiri 2018).

\section{Molecular parameters}

Leaf and root proline contents were determined using the acidic ninhydrin colorimetric assay (Bates et al. 1973). Proline concentrations were calculated as described in Abrahám et al. (2010) with 0.1 g homogenized tissue sample. The absorbance (A) was measured at $520 \mathrm{~nm}$ using toluene as reference. A standard curve with $A_{520}$ values of proline standard $(5-500 \mu \mathrm{g} / \mathrm{ml})$ was used to calculate the concentration of the samples.

Leaf chlorophyll content was determined following extraction of leaf tissue $(0.1 \mathrm{~g})$ in methanol as described by Warren (2008). $A_{652}, A_{665}$, and $A_{470}$ were measured using methanol as reference.

Crude protein extraction for antioxidant enzyme activity measurements was performed with $0.1 \mathrm{~g}$ ground leaf tissue. Fresh Tissues were homogenized in $1 \mathrm{ml}$ of ice-cold $100 \mathrm{mM}$ PBS (pH 7.8 with $0.1 \mathrm{mM}$ EDTA) and the supernatant was collected after $20 \mathrm{~min}$ centrifugation at $13.000 \mathrm{~g}, 4^{\circ} \mathrm{C}$. The concentration of the crude protein extract was spectrophotometrically calculated using the Warburg-Christian formula (Simonian and Smith 2001).

Catalase (CAT) activity was determined as described by Chen and Zhang (2016) by measuring the change in $\mathrm{OD}_{240}$ in $50 \mu \mathrm{l}$ crude extract every $10 \mathrm{sec}$ for $2 \mathrm{~min}$. Ascorbate peroxidase (APX) activity was determined as described by Elavarthi and Martin (2010) by measuring the change in $\mathrm{OD}_{290}$ in $90 \mu \mathrm{l}$ crude extract due to ascorbate oxidation of in the reaction every 15 sec for $3 \mathrm{~min}$. The basal level of ascorbate oxidation was measured using PBS (pH 7.0) instead of crude extract.

\section{Ion contents}

Ground root and leaf tissue samples were oven-dried at $80^{\circ} \mathrm{C}$. Tissue samples $\left(0.1 \mathrm{~g}\right.$ ) were mixed with $10 \mathrm{ml} \mathrm{HNO}_{3}$ and $5 \mathrm{ml} \mathrm{H}_{2} \mathrm{O}_{2}$. The digestion was achieved by heating the samples $10 \mathrm{~min}$ at $100^{\circ} \mathrm{C}$, then $15 \mathrm{~min}$ at $150^{\circ} \mathrm{C}$, and finally $15 \mathrm{~min}$ at $180^{\circ} \mathrm{C}$. Solution volume was adjusted to $25 \mathrm{ml}$ with $\mathrm{dH}_{2} \mathrm{O}$. Sodium, calcium, potassium, and magnesium ion concentrations were measured by inductively coupled atomic emission spectrometry (Agilent 700 Series ICP-OES, Agilent, US).

\section{Statistical analysis and correlation}

Statistical analyses were performed with Graphpad Prism version 9.1.2 for Windows (GraphPad Software, San Diego, California USA, "www.graphpad.com"). RT-qPCR for pvSPS4 knock-down in different lines was analyzed with One-Way Anova (Brown- 
Forsythe and Welch test) and multiple comparisons were performed with Dunnet's T3. Data of RT-qPCR for SPS homologs and WB were analyzed with parametric t-test due to the relative nature of measurements. Analysis of other physiological, molecular and ion content measurements were performed with 2-Way-Anova. Multiple comparisons for control vs treatment conditions were implemented with Sidak's test and displayed with black outlines. Control vs control and treatment vs treatment comparisons between lines were done with Tukey's test: Control comparisons were displayed with blue outlines and treatment

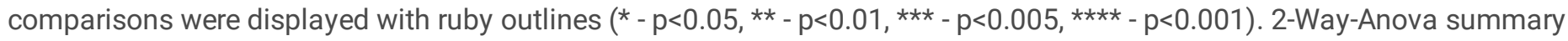
results were given in Table S1, S2 and S3. Correlations of the responses of the lines to salt stress was assessed with Spearman's Rank Order correlation.

\section{Results}

Knock-down of root pvSPS4 does not induce high expression of other SPS homologs

The main methodology of this study, A.rhizogenes mediated transformation, has a highly variable efficiency that depends on the species of interest and the approach that is employed (Estrada-Navarrete et al. 2007; Bandaranayake and Yoder 2018; Xu et al. 2020). To confirm the success of the transformation, following the growth of hairy roots (Fig. 1a) and excision of the primary roots, we have verified the genomic insertion by the visualization of dsRed fluorescent protein that is downstream of a constitutive promoter (Fig. 1b-c). The visualization of fluorescence was performed with both non-destructive (Fig. 1b) and destructive (Fig. 1c-d) methods. The efficiency of the transformation was evaluated with the analysis of 150 separate root tissues of which 123 displayed red fluorescence indicating an $82 \%$ transformation rate. As this is in range with the proposed transformation efficiency of the methodology (Estrada-Navarrete et al. 2007) we proceeded to assessment of RNAi efficacy.

RT-qPCR analysis confirmed the knock-down of pvSPS4 gene under treatment conditions in SucPho roots while the Blank and HumFer plants roots have displayed an upregulation pattern for pvSPS4 under salt stress as expected (Fig. 1e) Under control conditions, pvSPS4 expression did not alter for either HumFer or SucPho roots (Fig S1). WB analysis demonstrated stable control and treatment pvSPS4 levels in Blank and SucPho roots. The knock-down caused a $39.24 \%$ decrease $(p<0.01)$ in pvSPS4 protein levels for the SucPho roots under salt treatment conditions. No significant difference was observed for pvSPS4 levels in control conditions among lines (Fig. 1f).

All organisms are able to endure genetic modifications and disruptions and prolong their fitness through genetic robustness. This capability can be due to genetic redundancy which is the compensation for the inadequacy of one gene by an alternative with analogous function (Tautz 1992). Although there are nine SPS homologs in the P.vulgaris genome, only two of them, Phvul.003G170100 (pvSPS1) and Phvul.006G031700 (pvSPS3), possess high amino acid sequence similarity (54\% and 57\% respectively) with pvSPS4. The transcriptome analysis in our previous study has demonstrated that $p v S P S 4$ and its homolog pvSPS1 have root-specific expression patterns with high transcription rates. However, pvSPS1 presented stable expression under control conditions and salinity stress, unlike pvSPS4. The other SPS homolog, pvSPS3, had very low transcript levels in wild-type root tissues, but a high level of expression in leaves. pvSPS3 also displayed a upregulation in the leaves upon salt stress which indicates a leaf-specific regulation for this gene (Niron et al. 2020).

The effect of pvSPS4 knock-down on the mentioned SPS homologs, in the hairy roots, was first analyzed with RT-qPCR to investigate their potential for compensation of knock-down by an upregulation. Knock-down of pvSPS4 did not induce differential expression of pvSPS1 upon salt treatment. In response to salinity, pvSPS3 demonstrated a significant downregulation (Fig. 2a). Since pvSPS1 is the root-specific homolog, we measured pvSPS1 protein levels with Elisa. The pvSPS1 protein displayed a small but significant increase (approx. 1.3-fold) in SucPho roots in control, but there was no further increase in treatment conditions (Fig. 2b). Also, SucPho roots displayed higher pvSPS1 protein levels under salt stress compared to HumFer but not Blank roots. Anova results for ELISA (Table S1) demonstrated that the increase of pvSPS1 amount in SucPho roots was significantly related to knock-down but not salt treatment.

pvSPS4 knock-down changes the root glucose/sucrose ratio in both control and salt-stress conditions 
As SPS genes are associated with the regulation of carbohydrate metabolism and its partitioning, we investigated the effect of pvSPS4 knock-down on root systems glucose and sucrose contents (Fig. 3). The only significant change in glucose levels was a doubling of glucose levels in SucPho roots which decreased to control levels under salt stress. There was no effect on sucrose levels (Fig. 3a). Anova results demonstrated that knock-down, salt treatment and their interaction had significant effects on the divergence in glucose levels (Table S1).

The divergence in glucose amount has reflected on the glucose/sucrose ratio in SucPho roots as it displayed a significant increase in the control and a significant decrease under salt stress compared to Blank and HumFer roots indicated an imbalance of carbohydrate partitioning (Fig. 3b).

Changes in physiological parameters resulting from pvSPS4 knock-down

To understand the effects of pvSPS4 knock-down related root-sugar imbalance on carbon fixation and plant physiology, we examined the chlorophyll content (Fig. 4) surface area, water content, and membrane integrity of leaves (Fig. 5).

There was no significant difference between the control levels of $c h l a$, or $c h l b$ among the composite lines. Upon salt treatment, only SucPho plants showed a significant content reduction in both pigments, but much higher level in chl $b$. In treatment conditions SucPho chlorophyll levels were also significantly lower than Blank but not HumFer plants (Fig. 4a-b). Anova results showed that while both pigments were significantly affected by knock-down and salt treatment, but only chl $b$ was affected by the interaction of both (Table S1).

The Blank, HumFer, and SucPho lines presented similar phenotypes in control conditions, with a slight growth reduction observed in SucPho plants (Fig. 5a). A larger impact on growth was seen under salt stress: While the Blank plants appeared relatively healthy, SucPho plants were wilted and displayed signs of tissue necrosis. Performance of HumFer plants under salt stress, on the other hand, appeared to be in between the Blank and SucPho plants with observable indications of stress (Fig. 5a). The reduced growth of SucPho plants was apparent with a $45 \%$ reduction in leaf area as well while the loss was only minor for Blank and HumFer plants (Fig. 5b-c). Moreover, SucPho plants have demonstrated a major, 11\%, loss in leaf RWC under saline conditions while this loss was about $4 \%$ for both Blank and HumFer plants. (Fig. 5d). The effect of knock-down was not significant alone according to Anova results, yet the interaction of it with salt treatment was a significant player for the observed decrease (Table S2).

The leaf area and RWC losses under salt stress in the case of pvSPS4 knock-down suggested high cellular damage for leaf tissues of SucPho plants. Indeed, salt stressed SucPho leaf sections lost significantly more electrolytes on the 4th hour of the sectioning compared to Blank and HumFer leaf sections. On the 8th hour, the only significant difference was observed between Blank and SucPho (Fig. 5e). On the contrary, pvSPS4 knock-down did not produce a high electrolyte leakage in control conditions (Fig S2).

Sugar imbalance had negative effects on the ionic balance of the knock-down plants

Next, we have examined the effects of pvSPS4 knock-down related sugar imbalance on ion uptake, transport, and sodium accumulation by measuring, $\mathrm{K}^{+}, \mathrm{Ca}^{+2}, \mathrm{Mg}^{+2}$, and $\mathrm{Na}^{+}$contents of the root (Fig. 6) and leaf tissues (Fig. 7). pvSPS4 knock-down had a major effect on both uptake and transport of the $\mathrm{K}^{+}$: Blank and HumFer root $\mathrm{K}^{+}$levels acted in concert with previous results for Ispir genotype (Niron et. al. 2020) and dropped significantly under salt stress while SucPho root $\mathrm{K}^{+}$levels significantly increased (Fig. 6a) as observed in a salt susceptible genotype (Niron et. al. 2020). Moreover, the control $\mathrm{K}^{+}$content in the roots was significantly higher for Blank and HumFer than SucPho, but it was significantly lower in treatment conditions and interaction of knock-down and treatment was the major source for this variation (Table S3). Leaf tissues of all plants have reacted in a similar fashion with a significant accumulation of $\mathrm{K}^{+}$in response to salt stress, but the extent of change was different: $\mathrm{K}^{+}$levels increased by 1.25 and 1.35 -fold for Blank and HumFer roots respectively while the increase was 1.94 -fold for SucPho plants (Fig. 7a). 
In general, pvSPS4 knock-down has caused an imbalance in $\mathrm{Ca}^{+2}$ and $\mathrm{Mg}^{+2}$ contents in the tissues. Salt treated SucPho plants presented a significant decrease in $\mathrm{Ca}^{+2}$ content in both root and leaf tissues but there was no significant difference between the control and the treatment conditions in Blank and HumFer tissues (Fig. 6b and Fig. 7b). Salt treatment has resulted in a 1.97-fold decrease in SucPho roots while there was no significant difference in Blank and Humfer roots. In control conditions, both Blank and HumFer roots displayed significantly lower levels of $\mathrm{Ca}^{+2}$. In treatment conditions, on the other hand, only Blank roots maintained significantly higher levels of $\mathrm{Ca}^{+2}$ (1.59-fold) than SucPho roots (Fig. 6b). In the leaf tissues of SucPho plants, Ca+2 levels were much higher than Blank and Humfer plants (1.81 and 2.16-fold respectively) in control conditions. Salinity elicited a steep decrease that has brought SucPho leaf $\mathrm{Ca}^{+2}$ to similar levels of HumFer, yet Blank leaves had significantly higher $\mathrm{Ca}^{+2}$ content in treatment conditions compared to others (Fig. 7b). For both tissues, interaction of salt treatment and knock-down was the major source of the variation observed (Table S3).

Blank and HumFer roots did not show a significant change in $\mathrm{Mg}^{+2}$ levels under saline conditions, but SucPho roots presented a significant decline (2.77-fold). Anova results displayed knock-down as the main source of variation here (Table S3). And, even though control $\mathrm{Mg}^{+2}$ levels were similar for roots of all composite lines, Blank roots have accumulated significantly more $\mathrm{Mg}^{+2}$ compared to both HumFer and SucPho roots (Fig. 6c). Leaf $\mathrm{Mg}^{+2}$ contents displayed a similar response as Ca ${ }^{+2}$ : Blank and HumFer leaf $\mathrm{Mg}^{+2}$ levels did not show a significant change upon salt stress. Although SucPho leaf $\mathrm{Mg}^{+2}$ content in control was lower than both Blank and Humfer to begin with, when exposed to stress conditions, it displayed a steep 1.69-fold increase. The SucPho leaf $\mathrm{Mg}^{+2}$ control level was significantly lower compared to Blank and HumFer leaves while it was significantly higher in treatment conditions (Fig. 7c). In contrast to roots, interaction of knock-down with salt treatment was the main source of variation for leaf $\mathrm{Mg}^{+2}$ levels (Table S3).

All plants presented a majorly significant $\mathrm{Na}^{+}$upsurge in the case of salt treatment and there was no significant difference between the control or treatment levels of tissues (Fig. 6d and Fig. 7d). On the other hand, roots displayed a meaningful difference for salt-related $\mathrm{Na}^{+}$uptake regulation in the case of pvSPS4 knock-down: SucPho roots accumulated significantly higher $\mathrm{Na}^{+}$compared to Blank and HumFer roots under saline conditions. Interestingly HumFer roots accumulated even lower amount of $\mathrm{Na}^{+}$than Blank roots (Fig. 6d).

Osmoprotection and antioxidant capacity have dropped for SucPho plants

To interpret the physiological consequences of root pvSPS4 knock-down on the tissues, we examined the changes in osmoprotection and antioxidant capacities of the composite lines (Fig. 8). Both systems are known to be highly salt stressresponsive, and a decrease in capacity signifies the increase in sensitivity to stress (reviewed in Parida and Das 2005). Content analysis of proline, a key osmoprotectant (Hayat et al. 2012), in leaves and roots helped us infer the osmoprotection capability of the composite lines in response to salt stress. Curiously, leaf tissues of all lines accumulated significantly different levels of proline from each other in control conditions. Upon salt stress, all composite lines managed to significantly increase their proline content, but to different extents. Blank leaf proline levels have increased by 17.95 -fold, while HumFer leaf proline levels have displayed a 3.51-fold upsurge; for SucPho leaves the increase was only 1.63-fold (Fig. 8a).

For root tissues in control conditions, Blank roots accumulated a significantly higher amount of proline compared to HumFer and SucPho roots. Nonetheless, the root proline levels of Blank and HumFer plants displayed a moderate but significant increase (1.91 and 2.01-fold respectively) as a salt stress response, but such increase was absent in SucPho roots (Fig. 8b).

A perturbed antioxidant removal capacity for leaves of the SucPho plants was observed under salt stress (Fig. 8c, d). In control conditions, pvSPS4 knock-down did not cause a significant change in leaf APX activity but SucPho leaves could not manage to increase APX activity under stress conditions as well. On the other hand, APX activity of Blank and HumFer leaves increased by 4.77 and 7.95-fold respectively (Fig. 8c). Similarly, SucPho leaves did not demonstrate any escalation in CAT activity in saline conditions in contrast to Blank leaves which presented more than a 1.5-fold increase, but such response was also absent in HumFer plants as well.

The correlation of responses was higher for Blank and HumFer than SucPho 
Although most of the physiological and molecular responses of Blank and HumFer plants to salt stress were similar to each other and deviated from the responses of SucPho plants, there were noteworthy differences between them in control and treatment conditions when compared separately. The adopted methodology introduced another variable, separate from the salt stress application, with the activation of RNAi machinery. Thus, we mapped all the results for the salt stress response of the lines together in the $\log _{2}$ scale to visualize the variation among them (Fig. 9a). Responses of the Blank (black) and HumFer (yellow) plants presented a highly overlapping pattern compared to SucPho (red) in the map. Moreover, we performed a correlation analysis to measure the resemblance of the response patterns of the lines (Fig. 9b). Responses of Blank and HumFer plants displayed very high correlation with Spearman r-value of 0.95 . On the other hand, root pvSPS4 knock-down caused a major decrease in correlation level. These results demonstrated the extent of the knock-down of the gene over the influence of RNAi machinery on the stress response.

\section{Discussion}

Soil salinity has become a global crisis that causes many adverse effects on crop development and productivity. Salinity generates intricate problems that disturb nutrient uptake, and general metabolism that result in decreased growth rate. These adverse effects include obstruction of root function in water absorption, as well as the impediment of physiological and molecular processes such as uptake and assimilation of nutrients (Carillo et al. 2011).

Soluble sugar metabolism under stress conditions is composed of complex and dynamic processes including simultaneous synthesis and catabolic reactions. It is connected to fluctuations in carbon fixation, alterations in source-sink partitioning, and transcriptional responses (Roitsch 1999; Gibson 2005; Rosa et al. 2009). In the sink tissues such as root, soluble sugars are subjected to rapid interconversion: Sucrose is catabolized into glucose and fructose, as these hexoses can initiate resynthesis of sucrose (Roitsch 1999). Sucrose and glucose are versatile metabolites taking part in the regulation of various biochemical and molecular functions such as development, energy partition, metabolite production, signaling, and osmoregulation under stress conditions (Braun et al. 2014; Hennion et al. 2019). That is why understanding their regulation is important to identify the connections between these salt stress-responsive networks.

Sucrose resynthesis in the roots by the activity of sucrose metabolism enzymes such as SPS is deemed to be essential for its storage or intercellular transport. Sink SPS metabolism has been linked with protein storage (Weber et al. 1997), starch accumulation (Cheng and Chourey 1999), cellulose production (Babb and Haigler 2001), and it can be crucial for proper regulation of carbohydrate partitioning (Cheng and Chourey 1999). However, molecular evidence about sucrose resynthesis and the role of SPS activity in sinks, particularly under stress conditions, is still limited. To address this issue, in this study, we have investigated the effect of the knock-down of root-specific, salt-responsive common bean SPS homolog, pvSPS4, under salt stress.

We have utilized A.rhizogenes mediated hairy root induction to generate composite plants with pvSPS4 knock-down through RNAi. Two experimental control lines were constructed to compare the effects of pvSPS4 knock-down: Blank line with no vector insertion to use as the main background, and HumFer line with RNAi triggered to function as a background purely to evaluate the outcomes of RNAi activity. RNAi off-target effects can arise when short interfering RNAs (siRNAs) alter the expression of genes different from their target (Birmingham et al. 2006; Jackson 2006). There is cumulating evidence that some of these off-target effects are result of siRNAs operating as microRNAs (miRNAs), targeting mRNAs that include partial sequence matches to the siRNAs (Saxena et al. 2003; Birmingham et al. 2006; Aleman et al. 2007). In this regard, the observed phenotype dissimilarities between HumFer and Blank lines are reasonable since in HumFer plants, the RNAi machinery is active. Nonetheless, SucPho line was demonstrated to have significant complications on the salt tolerance mechanism, compared to both HumFer and Blank, by correlation analysis (Fig. 9).

pvSPS4 may regulate ionic balance through the adjustment of sugar balance in the roots

Though pvSPS4 was upregulated under stress conditions for Blank and HumFer roots, the protein levels were stable. But SucPho roots displayed a nearly $40 \%$ reduction in pvSPS4 protein content under salt treatment implying a high turnover rate for this enzyme in such conditions. pVSPS4 knock-down resulted in pVSPS3 downregulation under treatment conditions in the roots and 
increase in pvSPS1 protein content in both conditions. Although we did not observe significant decrease in transcription or protein content of pVSPS4 in control conditions, we might conclude that knock-down caused a problem in SPS enzyme balance in the root tissues which might be the main source of differences observed in SucPho plants in control conditions.

pvSPS4 knock-down caused an overall 1.92-fold higher glucose accumulation in control conditions in the roots, yet the sucrose levels did not change. On the other hand, there was no significant difference in glucose or sucrose levels among the lines in treatment conditions. Nonetheless, the differences between the contents have reflected on the glucose/sucrose ratio of the lines. The imbalance was apparent in SucPho lines with significant disparity in control condition (Fig. 3b). The change in this ratio for SucPho roots was overall 2.71 times higher than the roots of other lines upon salt treatment. Interestingly, in our previous study, a similar difference was observed between the roots of the salt-tolerant Ispir and salt-susceptible TR43477 genotypes, with the latter displaying a 2.35 times greater decrease under salt-stress (Niron et al. 2020). The similarity of this variation suggests that it can be a key subject for the salt tolerance response. Since these sugars have major and independent roles in regulatory signaling (Chiou and Bush 1998; Moore 2003; Sarowar et al. 2008; Cho et al. 2009; Tauzin and Giardina 2014; Martínez-Noël and Tognetti 2018; Ahmad 2019), variations in the sucrose-hexose ratio can have negative impacts on the signal transduction relays. In turn, these sugar-sensing pathways can affect the sucrose metabolism (Koch et al. 1992; Roitsch et al. 1995; Stitt and Hurry 2002), creating a feedback loop. Therefore, it is reasonable to deduce that balance adjustment of these sugars is crucial for a decent stress response.

The pVSPS4 knock-down also resulted in an ionic imbalance in leaf and root tissues under control conditions, which was intensified under salt stress when compared to the other two lines. The imbalance was apparent for $\mathrm{K}^{+}$in SucPho roots (Fig. 6a), there was a steep contrast in $\mathrm{Ca}^{+2}$ content for both conditions in both tissues (Fig. 6b and Fig. 7b) and SucPho plants could not manage to balance $\mathrm{Mg}^{+2}$ levels in the leaves (Fig. 7c). However, this imbalance did not yield a major difference in $\mathrm{Na}^{+}$ accumulation for SucPho plants. Although SucPho roots accumulated significantly higher $\mathrm{Na}^{+}$, this did not affect the leaf $\mathrm{Na}^{+}$ levels (Fig. 6d and Fig. 7d).

There are several routes that a glucose/sucrose imbalance can be linked to ionic imbalance: Both sucrose and glucose function as osmolytes and maintain homeostasis in the cell (Gupta and Kaur 2005), yet sucrose is much more common and crucial in osmoregulation than glucose (Slama et al. 2015). Furthermore, both sugars were demonstrated to regulate membrane potential in different extents (Franz and Tattar 1981), and both $\mathrm{K}^{+}$and $\mathrm{Ca}^{+2}$ uptake are strongly related to membrane polarization status of the cell (Geiger et al. 1998; Miedema et al. 2001, 2008). Notably, $\mathrm{K}^{+}$ions have to move against their concentration gradient to enter the root. To make this movement energetically favorable, the activity of $\mathrm{H}^{+}$-ATPases, which are displayed to be induced by sucrose (Mito et al. 1996) are required (Nieves-Cordones et al. 2014). Thus, a lack of balance between glucose and sucrose in the root tissues might have disrupted the maintenance of cellular osmolarity, membrane potential, and $\mathrm{H}^{+}$gradient, especially in the case of salt stress, and resulted in dysregulation of ion uptake mechanisms in common bean.

Another potential route for glucose/sucrose imbalance to cause the ionic disorder is the disruption of the expressional regulation of circadian clock genes. Studies have displayed the connections between the circadian clock, immunity, and the sugars in plants (Roden and Ingle 2009; Bolouri Moghaddam and Van den Ende 2013). The clock genes were found to be in strong interplay with sucrose levels and invertases - enzymes that catalyze sucrose to hexose - which indicates that the fine regulation of hexose/sucrose ratio is vital for an appropriate stress-response (Haydon et al. 2013). Furthermore, a properly functioning clock is necessary for the regulation of cellular auxin levels and response to it in the root tissues (Voß et al. 2015). Auxin is a potent inducer of $\mathrm{K}^{+}$uptake through the regulation of $\mathrm{H}^{+}$pumps (Marten et al. 1991; Lohse and Hedrich 1992) and it possesses a crucial role in the intercellular $\mathrm{Ca}^{+2}$ and $\mathrm{K}^{+}$transport and $\mathrm{Ca}^{+2}$ signaling through cation channel activation (Philippar et al. 1999; Shishova and Lindberg 2004; Kirpichnikova et al. 2014). Therefore, the disproportion in SucPho root $\mathrm{K}^{+}$and $\mathrm{Ca}^{+2}$ contents in both control and salt treatment conditions can be due to disturbance of auxin regulation through the circadian clock. Moreover, $\mathrm{Ca}^{+2}$ content and signaling were shown to be vital in modifying the selectivity and absorption of other ions, including magnesium (Tang and Luan 2017), for proper salt tolerance in various plants (Epstein 1961; Rains and Epstein 1967; Zhu 2002) which might explain the significant changes in $\mathrm{Mg}^{+2}$ levels for SucPho plants upon treatment. 
The plant circadian clock of different organs has been demonstrated to be dependent (James et al. 2008) so, any disruption of the clock through the glucose/sucrose imbalance in one part of the plant can be expected to affect other parts as well. Moreover, any interruption in $\mathrm{Ca}^{+2}$ signaling holds potential to have major negative effects on $\mathrm{K}^{+}$levels and transport (Ivashikina et al. 2005; Cheong et al. 2007; Lan et al. 2011; Ren et al. 2013) which is tightly coupled with the regulation of source to sink nutrient transportation including sucrose (Geiger et al. 1998). Hence, a disturbance in the root circadian clock together with $\mathrm{Ca}^{+2}$ signaling may have been the main reason for the transmission of resulting complications to the upper parts of the plant.

The disruption of ionic regulation and possibly shoot-to-root transport had resulted in an impaired salt stress response for the leaf tissues in SucPho plants. Leaves displayed reduced chlorophyll content (Fig. 4) and compromised physiology (Fig. 5). As our previous study implied, preservation of chlorophyll levels is crucial for an effective salt tolerance response (Niron et al. 2020), so understanding the mechanism that caused chlorophyll decrease in SucPho leaves upon salt stress is critical to interpret other physiological consequences. Leaf $\mathrm{Ca}^{+2}$ and $\mathrm{Mg}^{+2}$ levels presented both conditional and directional contrasts for SucPho plants (Fig. $7 \mathrm{~b}$ and c). $\mathrm{Mg}^{+2}$ is a major element in chlorophyll metabolism (Masuda 2008) and takes role in Rubisco activation (Portis and Jr. 2003). An uneven rise in the $\mathrm{Mg}^{+2}$ content might have been responsible for the disruptions in chlorophyll synthesis in SucPho leaves. Furthermore, it might have had negative effects on the TCA cycle and amino acid synthesis as well (Kwon et al. 2019). $\mathrm{Ca}^{+2}$ also holds key roles in photosynthesis (Wang et al. 2019), energy production (Stael et al. 2012) and regulation of salt stress responses in plants (Manishankar et al. 2018). Therefore, the combined effect of $\mathrm{Mg}^{+2}$ and Ca ${ }^{+2}$ imbalance in the leaves has potential to cause the growth reduction as implied by leaf area measurements (Fig. $5 \mathrm{a}$, b, and c) and interrupt a proper salt stress response in SucPho plants.

Moreover, leaf and root tissues of SucPho plants, in contrast to Blank and HumFer plants, could not manage to accumulate the major osmoprotectant proline (Hayat et al. 2012) in response to salt stress (Fig. 8a, b) which suggested a turmoil in osmoregulation capacity for SucPho. Indeed, the leaves of SucPho plants lost significantly more water compared to other lines (Fig. 5d). This problem might be caused by the above-mentioned disruptions in photosynthesis and energy metabolism together with the effect of $\mathrm{Mg}^{+2}$ accumulation on amino-acid synthesis. Another suspect for the inadequacy in proline production can be the disruption of $\mathrm{Ca}^{+2}$ signaling which is known to play a major role in the regulation of proline accumulation upon ionic stress conditions (Parre et al. 2007).

Salt stress, in addition to osmotic and ionic factors, induces oxidative stress with a rise in reactive oxygen species (ROS) (de Azevedo Neto et al. 2006). A decline in water content leads to stomatal closure and a related drop in $\mathrm{CO}_{2}$ content, a vital electron acceptor, which then results in the over-production of ROS (Noctor 2002; Laxa et al. 2019). As SucPho leaves experienced a higher rate of RWC loss in stress conditions compared to Blank and HumFer lines (Fig. $5 \mathrm{~d}$ ), it is safe to presume that they also produced more ROS as well. Yet, the oxidative stress did not evoke a strong APX (Fig. 8c) activity in the SucPho leaves as it did in Blank and HumFer leaves. The lack of a sufficient amount of proline, which was demonstrated to have antioxidant enzyme regulatory function (Öztürk and Demir 2002) as well as OH· scavenging roles (Gill and Tuteja 2010) may have aggravated the detrimental effects of such oxidative stress in SucPho leaves. Availability and balance of $\mathrm{Ca}^{+2}$ are also imperative for a proper antioxidant response under stress conditions (Ben Amor et al. 2010; Seifikalhor et al. 2019) so the imbalance in $\mathrm{Ca}^{+2}$ is another potential actor in this disruption. As the cellular membranes are highly prone to damage by ROS (Blokhina 2003), the significantly elevated electrolyte leakage for the SucPho leaves under stress conditions (Fig. 5e) can be associated with the insufficient antioxidant removal capacity of SucPho.

In conclusion, pvSPS4 knock-down in the roots of common bean has disrupted the glucose/sucrose balance in the root tissues which in turn obstructed the constitution of ionic balance under salt stress. $\mathrm{K}^{+}$and $\mathrm{Ca}^{+2}$ imbalances in the root system possibly had negative outcomes in the root-to-shoot nutrient transport system and invoked a Ca ${ }^{+2}$ and $\mathrm{Mg}^{+2}$ imbalance in the leaf tissues. The adverse effects of ionic disproportion together with declined water availability in the leaves, distorted the photosynthesis and possibly energy production metabolism; reduced the growth, and resulted in increased cellular damage due to interruption of osmoprotection and antioxidant removal machinery. Considering the extent of salt susceptibility which the knock-down of the 
pvSPS4 caused, it is safe to say that this sugar metabolism gene holds a critical role in salt-tolerance pathways and deserves attention in the future development of salt-tolerant varieties.

\section{Declarations}

\section{Author Contribution}

$\mathrm{HN}$ and MT conceived and designed the research. HN conducted the experiments and data collection (except for ICP-OES measurements). ICP-OES measurements were conducted by Yildiz Technical University Merklab. HN performed the statistical analysis of the data. HN and MT wrote the manuscript.

All authors read and approved the manuscript.

\section{Conflict of Interest}

The authors declare no conflict of interest.

\section{Funding}

This work was financially supported by Bogazici University Research Funds [BAP 16842]. The funder had no role in study design, data collection, and analysis, decision to publish, or preparation of the manuscript.

\section{Acknowledgements}

We thank Dr. Steven Footitt (Bogazici University, TR) for his valuable suggestions and editing the manuscript. We thank Dr. Igor Kryvoruchko (Bogazici University, TR) for his help with statistical analysis of the data. We also thank Dr. Ayşe Candayan (Bogazici University, TR) for final proofreading and editing of the manuscript.

We thank Dr. Roger Y. Tsien (University of California, US) for providing the pK7GWIWG2_II-RedRoot vector. Finally, we would like to thank Dr. Vojta Hudzieczek (Czech Academy of Sciences, CZ) for supplying the A. rhizogenes strain K599.

\section{References}

1. Abrahám E, Hourton-Cabassa C, Erdei L, Szabados L (2010) Methods for determination of proline in plants. Methods in molecular biology (Clifton, NJ). https://doi.org/10.1007/978-1-60761-702-0_20

2. Ahmad IZ (2019) Role of Sugars in Abiotic Stress Signaling in Plants. Plant Signaling Molecules. Elsevier, pp 207-217

3. Aleman LM, Doench J, Sharp PA (2007) Comparison of siRNA-induced off-target RNA and protein effects. RNA 13:385-395. https://doi.org/10.1261/rna.352507

4. Amirjani MR (2010) Effect of Salinity Stress on Growth, Sugar Content, Pigments and Enzyme Activity of Rice. International $\mathrm{J}$ of Botany 7:73-81. https://doi.org/10.3923/ijb.2011.73.81

5. Babb VM, Haigler CH (2001) Sucrose Phosphate Synthase Activity Rises in Correlation with High-Rate Cellulose Synthesis in Three Heterotrophic Systems. Plant Physiol 127:1234-1242. https://doi.org/10.1104/pp.010424

6. Bandaranayake PCG, Yoder $\mathrm{JI}$ (2018) Factors affecting the efficiency of Rhizobium rhizogenes root transformation of the root parasitic plant Triphysaria versicolor and its host Arabidopsis thaliana. Plant Methods 14:61.

https://doi.org/10.1186/s13007-018-0327-2

7. Barbas CF, Burton DR, Scott JK, Silverman GJ (2007) Quantitation of DNA and RNA. https://doi.org/10.1101/pdb.ip47. CSH protocols 2007:pdb.ip47 
8. Barrs H, Weatherley P (1962) A Re-Examination of the Relative Turgidity Technique for Estimating Water Deficits in Leaves. Australian Journal of Biological Sciences 15:413. https://doi.org/10.1071/BI9620413

9. Bates LS, Waldren RP, Teare ID (1973) Rapid determination of free proline for water-stress studies. Plant Soil 39:205-207. https://doi.org/10.1007/BF00018060

10. Baxter CJ, Foyer $\mathrm{CH}$, Turner $\mathrm{J}$ et al (2003) Elevated sucrose-phosphate synthase activity in transgenic tobacco sustains photosynthesis in older leaves and alters development. J Exp Bot 54:1813-1820. https://doi.org/10.1093/jxb/erg196

11. Ben Amor N, Megdiche W, Jiménez A et al (2010) The effect of calcium on the antioxidant systems in the halophyte Cakile maritima under salt stress. Acta Physiol Plant 32:453-461. https://doi.org/10.1007/s11738-009-0420-2

12. Bilska-Kos A, Mytych J, Suski S et al (2020) Sucrose phosphate synthase (SPS), sucrose synthase (SUS) and their products in the leaves of Miscanthus $\times$ giganteus and Zea mays at low temperature. Planta 252:23. https://doi.org/10.1007/s00425020-03421-2

13. Birmingham A, Anderson EM, Reynolds A et al (2006) 3' UTR seed matches, but not overall identity, are associated with RNAi off-targets. Nat Methods 3:199-204. https://doi.org/10.1038/nmeth854

14. Blokhina O (2003) Antioxidants, Oxidative Damage and Oxygen Deprivation Stress: a Review. Ann Botany 91:179-194. https://doi.org/10.1093/aob/mcf118

15. Bolouri Moghaddam MR, Van den Ende W (2013) Sweet immunity in the plant circadian regulatory network. J Exp Bot 64:1439-1449. https://doi.org/10.1093/jxb/ert046

16. Braun DM, Wang L, Ruan Y-L (2014) Understanding and manipulating sucrose phloem loading, unloading, metabolism, and signalling to enhance crop yield and food security. J Exp Bot 65:1713-1735. https://doi.org/10.1093/jxb/ert416

17. Broughton WJ, Hernández G, Blair M et al (2003) Beans (Phaseolus spp.) - model food legumes. Plant Soil 252:55-128. https://doi.org/10.1023/A:1024146710611

18. Carillo P, Grazia M, Pontecorvo G et al (2011) Salinity Stress and Salt Tolerance. In: Shanker A (ed) Abiotic Stress in Plants Mechanisms and Adaptations. InTech

19. Chen J-G (2007) Sweet Sensor, Surprising Partners. Science's STKE 2007:pe7-pe7.

https://doi.org/10.1126/stke.3732007pe7

20. Chen S, Hajirezaei M, Börnke F (2005) Differential Expression of Sucrose-Phosphate Synthase Isoenzymes in Tobacco Reflects Their Functional Specialization during Dark-Governed Starch Mobilization in Source Leaves. Plant Physiol 139:1163-1174. https://doi.org/10.1104/pp.105.069468

21. Chen T, Zhang B (2016) Measurements of Proline and Malondialdehyde Content and Antioxidant Enzyme Activities in Leaves of Drought Stressed Cotton. https://doi.org/10.21769/BioProtoc.1913. BIO-PROTOCOL 6:

22. Cheng W-H, Chourey PS (1999) Genetic evidence that invertase-mediated release of hexoses is critical for appropriate carbon partitioning and normal seed development in maize. Theor Appl Genet 98:485-495.

https://doi.org/10.1007/s001220051096

23. Cheong YH, Pandey GK, Grant JJ et al (2007) Two calcineurin B-like calcium sensors, interacting with protein kinase CIPK23, regulate leaf transpiration and root potassium uptake in Arabidopsis: CBL-CIPK network in drought and low-K responses. Plant J 52:223-239. https://doi.org/10.1111/j.1365-313X.2007.03236.x

24. Chinnusamy V, Jagendorf A, Zhu J-K (2005) Understanding and Improving Salt Tolerance in Plants. Crop Sci 45:437. https://doi.org/10.2135/cropsci2005.0437

25. Chiou T-J, Bush DR (1998) Sucrose is a signal molecule in assimilate partitioning. Proceedings of the National Academy of Sciences 95:4784-4788. https://doi.org/10.1073/pnas.95.8.4784

26. Cho J-I, Ryoo N, Eom J-S et al (2009) Role of the Rice Hexokinases OsHXK5 and OsHXK6 as Glucose Sensors. Plant Physiol 149:745-759. https://doi.org/10.1104/pp.108.131227

27. Chua TK, Bujnicki JM, Tan T-C et al (2008) The Structure of Sucrose Phosphate Synthase from Halothermothrix orenii Reveals Its Mechanism of Action and Binding Mode. Plant Cell 20:1059-1072. https://doi.org/10.1105/tpc.107.051193 
28. Coruzzi G, Bush DR (2001) Nitrogen and Carbon Nutrient and Metabolite Signaling in Plants. Plant Physiol 125:61-64. https://doi.org/10.1104/pp.125.1.61

29. de Azevedo Neto AD, Prisco JT, Enéas-Filho J et al (2006) Effect of salt stress on antioxidative enzymes and lipid peroxidation in leaves and roots of salt-tolerant and salt-sensitive maize genotypes. Environ Exp Bot 56:87-94. https://doi.org/10.1016/j.envexpbot.2005.01.008

30. Du Y, Zhao Q, Chen L et al (2020) Effect of Drought Stress during Soybean R2-R6 Growth Stages on Sucrose Metabolism in Leaf and Seed. IJMS 21:618. https://doi.org/10.3390/ijms21020618

31. Elavarthi S, Martin B (2010) Spectrophotometric Assays for Antioxidant Enzymes in Plants. In: Sunkar R (ed) Plant Stress Tolerance. Humana Press, Totowa, NJ, pp 273-280

32. Epstein E (1961) The essential role of calcium in selective cation transport by plant cells. Plant Physiol 36:437-444. https://doi.org/10.1104/pp.36.4.437

33. Estrada-Navarrete G, Alvarado-Affantranger X, Olivares J-E et al (2007) Fast, efficient and reproducible genetic transformation of Phaseolus spp. by Agrobacterium rhizogenes. Nat Protoc 2:1819-1824. https://doi.org/10.1038/nprot.2007.259

34. Franz SL, Tattar TA (1981) Effect of Sugars and Amino Acids on Membrane Potential in Two Clones of Sugarcane. Plant Physiol 67:150-155. https://doi.org/10.1104/pp.67.1.150

35. Fresneau C, Ghashghaie J, Cornic G (2007) Drought effect on nitrate reductase and sucrose-phosphate synthase activities in wheat (Triticum durum L.): role of leaf internal CO2. J Exp Bot 58:2983-2992. https://doi.org/10.1093/jxb/erm150

36. Geigenberger P, Reimholz R, Deiting U et al (1999) Decreased expression of sucrose phosphate synthase strongly inhibits the water stress-induced synthesis of sucrose in growing potato tubers. Plant J 19:119-129. https://doi.org/10.1046/j.1365313X.1999.00506.X

37. Geiger $M$, Stitt $M$, Geigenberger $P$ (1998) Metabolism in slices from growing potato tubers responds differently to addition of sucrose and glucose. Planta 206:234-244. https://doi.org/10.1007/s004250050395

38. Gibson SI (2005) Control of plant development and gene expression by sugar signaling. Curr Opin Plant Biol 8:93-102. https://doi.org/10.1016/j.pbi.2004.11.003

39. Gifford RM, Thorne JH, Hitz WD, Giaquinta RT (1984) Crop Productivity and Photoassimilate Partitioning. Science 225:801808. https://doi.org/10.1126/science.225.4664.801

40. Gill SS, Tuteja N (2010) Reactive oxygen species and antioxidant machinery in abiotic stress tolerance in crop plants. Plant Physiol Biochem 48:909-930. https://doi.org/10.1016/j.plaphy.2010.08.016

41. Gupta AK, Kaur N (2005) Sugar signalling and gene expression in relation to carbohydrate metabolism under abiotic stresses in plants. J Biosci 30:761-776. https://doi.org/10.1007/BF02703574

42. Hatsugai N, Katagiri F (2018) Quantification of Plant Cell Death by Electrolyte Leakage Assay. https://doi.org/10.21769/BioProtoc.2758. BIO-PROTOCOL 8:

43. Hayat S, Hayat Q, Alyemeni MN et al (2012) Role of proline under changing environments: A review. Plant Signal Behav 7:1456-1466. https://doi.org/10.4161/psb.21949

44. Haydon MJ, Mielczarek O, Robertson FC et al (2013) Photosynthetic entrainment of the Arabidopsis thaliana circadian clock. Nature 502:689-692. https://doi.org/10.1038/nature12603

45. Hennion N, Durand M, Vriet C et al (2019) Sugars en route to the roots. Transport, metabolism and storage within plant roots and towards microorganisms of the rhizosphere. Physiol Plantarum 165:44-57. https://doi.org/10.1111/ppl.12751

46. Ho LC (1988) Metabolism and Compartmentation of Imported Sugars in Sink Organs in Relation to Sink Strength. Annu Rev Plant Physiol Plant Mol Biol 39:355-378. https://doi.org/10.1146/annurev.pp.39.060188.002035

47. Huber SC, Huber JL (1996) Role and Regulation of Sucrose-Phosphate Synthase in Higher Plants. Annu Rev Plant Physiol Plant Mol Biol 47:431-444. https://doi.org/10.1146/annurev.arplant.47.1.431

48. Huber SC, Huber JL (1992) Role of Sucrose-Phosphate Synthase in Sucrose Metabolism in Leaves. Plant Physiol 99:12751278. https://doi.org/10.1104/pp.99.4.1275

Page $14 / 29$ 
49. Ivashikina N, Deeken R, Fischer S et al (2005) AKT2/3 Subunits Render Guard Cell K+ Channels Ca2+ Sensitive. J Gen Physiol 125:483-492. https://doi.org/10.1085/jgp.200409211

50. Jackson AL (2006) Widespread siRNA "off-target" transcript silencing mediated by seed region sequence complementarity. RNA 12:1179-1187. https://doi.org/10.1261/rna.25706

51. James AB, Monreal JA, Nimmo GA et al (2008) The Circadian Clock in Arabidopsis Roots Is a Simplified Slave Version of the Clock in Shoots. Science 322:1832-1835. https://doi.org/10.1126/science.1161403

52. Jamil A, Riaz S, Ashraf M, Foolad MR (2011) Gene expression profiling of plants under salt stress. CRC Crit Rev Plant Sci 30:435-458

53. Kalt-Torres W, Huber SC (1987) Diurnal Changes in Maize Leaf Photosynthesis: III. Leaf Elongation Rate in Relation to Carbohydrates and Activities of Sucrose Metabolizing Enzymes in Elongating Leaf Tissue. Plant Physiol 83:294-298. https://doi.org/10.1104/pp.83.2.294

54. Kirpichnikova A, Rudashevskaya E, Yemelyanov V, Shishova M (2014) Ca2+-Transport through Plasma Membrane as a Test of Auxin Sensitivity. Plants 3:209-222. https://doi.org/10.3390/plants3020209

55. Koch KE, Nolte KD, Duke ER et al (1992) Sugar Levels Modulate Differential Expression of Maize Sucrose Synthase Genes. Plant Cell 59-69. https://doi.org/10.1105/tpc.4.1.59

56. Krapp A, Stitt M (1995) An evaluation of direct and indirect mechanisms for the ?sink-regulation? of photosynthesis in spinach: Changes in gas exchange, carbohydrates, metabolites, enzyme activities and steady-state transcript levels after cold-girdling source leaves. Planta 195. https://doi.org/10.1007/BF00202587

57. Kwon MC, Kim YX, Lee S et al (2019) Comparative Metabolomics Unravel the Effect of Magnesium Oversupply on Tomato Fruit Quality and Associated Plant Metabolism. Metabolites 9:231. https://doi.org/10.3390/metabo9100231

58. Lan W-Z, Lee S-C, Che Y-F et al (2011) Mechanistic Analysis of AKT1 Regulation by the CBL-CIPK-PP2CA Interactions. Mol Plant 4:527-536. https://doi.org/10.1093/mp/ssr031

59. Laxa M, Liebthal M, Telman W et al (2019) The Role of the Plant Antioxidant System in Drought Tolerance. Antioxidants 8:94. https://doi.org/10.3390/antiox8040094

60. Lichtenthaler HK, Buschmann C (2001) Chlorophylls and Carotenoids: Measurement and Characterization by UV-VIS Spectroscopy. Current Protocols in Food Analytical Chemistry 1:F4.3.1. https://doi.org/10.1002/0471142913.faf0403s01. F4.3.8

61. Livak KJ, Schmittgen TD (2001) Analysis of relative gene expression data using real-time quantitative PCR and the 2- $\Delta \Delta C T$ method. https://doi.org/10.1006/meth.2001.1262. Methods

62. Lohse G, Hedrich R (1992) Characterization of the plasma-membrane H+-ATPase from Vicia faba guard cells: Modulation by extracellular factors and seasonal changes. Planta 188:206-214. https://doi.org/10.1007/BF00216815

63. Lunn JE (2003) Sucrose-phosphatase gene families in plants. Gene 303:187-196. https://doi.org/10.1016/S03781119(02)01177-0

64. Lunn JE, MacRae E (2003) New complexities in the synthesis of sucrose. Curr Opin Plant Biol 6:208-214. https://doi.org/10.1016/S1369-5266(03)00033-5

65. Lutfiyya LL, Xu N, D'Ordine RL et al (2007) Phylogenetic and expression analysis of sucrose phosphate synthase isozymes in plants. J Plant Physiol 164:923-933. https://doi.org/10.1016/j.jplph.2006.04.014

66. Maness N (2010) Extraction and Analysis of Soluble Carbohydrates. In: Sunkar R (ed) Plant Stress Tolerance. Humana Press, Totowa, NJ, pp 341-370

67. Manishankar P, Wang N, Köster $P$ et al (2018) Calcium signaling during salt stress and in the regulation of ion homeostasis. J Exp Bot 69:4215-4226. https://doi.org/10.1093/jxb/ery201

68. Marten I, Lohse G, Hedrich R (1991) Plant growth hormones control voltage-dependent activity of anion channels in plasma membrane of guard cells. Nature 353:758-762. https://doi.org/10.1038/353758a0

69. Martínez-Noël GMA, Tognetti JA (2018) Sugar Signaling Under Abiotic Stress in Plants. Plant Metabolites and Regulation Under Environmental Stress. Elsevier, pp 397-406

Page $15 / 29$ 
70. Masuda T (2008) Recent overview of the Mg branch of the tetrapyrrole biosynthesis leading to chlorophylls. Photosynth Res 96:121-143. https://doi.org/10.1007/s11120-008-9291-4

71. Microsoft (2019) Analysis ToolPak - Complex Data Analysis. Microsoft, USA

72. Miedema H, Bothwell JHF, Brownlee C, Davies JM (2001) Calcium uptake by plant cells - channels and pumps acting in concert. Trends Plant Sci 6:514-519. https://doi.org/10.1016/S1360-1385(01)02124-0

73. Miedema H, Demidchik V, Véry A et al (2008) Two voltage-dependent calcium channels co-exist in the apical plasma membrane of Arabidopsis thaliana root hairs. New Phytol 179:378-385. https://doi.org/10.1111/j.1469-8137.2008.02465.x

74. Mito N, Wimmers LE, Bennett AB (1996) Sugar Regulates mRNA Abundance of H+-ATPase Gene Family Members in Tomato. Plant Physiol 112:1229-1236. https://doi.org/10.1104/pp.112.3.1229

75. Moore B (2003) Role of the Arabidopsis Glucose Sensor HXK1 in Nutrient, Light, and Hormonal Signaling. Science 300:332336. https://doi.org/10.1126/science.1080585

76. Muchate NS, Nikalje GC, Rajurkar NS et al (2016) Plant Salt Stress: Adaptive Responses, Tolerance Mechanism and Bioengineering for Salt Tolerance. The Botanical Review 82:371-406. https://doi.org/10.1007/s12229-016-9173-y

77. Munns R, Tester M (2008) Mechanisms of Salinity Tolerance. Annu Rev Plant Biol 59:651-681. https://doi.org/10.1146/annurev.arplant.59.032607.092911

78. Nieves-Cordones M, Alemán F, Martínez V, Rubio F (2014) K+ uptake in plant roots. The systems involved, their regulation and parallels in other organisms. J Plant Physiol 171:688-695. https://doi.org/10.1016/j.jplph.2013.09.021

79. Niron H, Barlas N, Salih B, Türet M (2020) Comparative Transcriptome, Metabolome, and lonome Analysis of Two Contrasting Common Bean Genotypes in Saline Conditions. Front Plant Sci 11. https://doi.org/10.3389/fpls.2020.599501

80. Noctor G (2002) Drought and Oxidative Load in the Leaves of C3 Plants: a Predominant Role for Photorespiration? Ann Botany 89:841-850. https://doi.org/10.1093/aob/mcf096

81. Öztürk L, Demir Y (2002) In vivo and in vitro protective role of proline. Plant Growth Regul 38:259-264. https://doi.org/10.1023/A:1021579713832

82. Parida AK, Das AB (2005) Salt tolerance and salinity effects on plants: a review. Ecotoxicol Environ Saf 60:324-349. https://doi.org/10.1016/J.ECOENV.2004.06.010

83. Parre E, Ghars MA, Leprince A-S et al (2007) Calcium Signaling via Phospholipase $C$ is Essential for Proline Accumulation upon Ionic But Not Nonionic Hyperosmotic Stresses in Arabidopsis. Plant Physiol 144:503-512. https://doi.org/10.1104/pp.106.095281

84. Peng J, Liu J, Zhang L et al (2016) Effects of Soil Salinity on Sucrose Metabolism in Cotton Leaves. PLoS ONE 11:e0156241. https://doi.org/10.1371/journal.pone.0156241

85. Philippar K, Fuchs I, Luthen H et al (1999) Auxin-induced K+ channel expression represents an essential step in coleoptile growth and gravitropism. Proceedings of the National Academy of Sciences 96:12186-12191.

https://doi.org/10.1073/pnas.96.21.12186

86. Portis AR Jr (2003) Rubisco activase - rubisco's catalytic chaperone. Photosynth Res 75:11-27. https://doi.org/10.1023/A:1022458108678

87. Rains DW, Epstein E (1967) Sodium Absorption by Barley Roots: Its Mediation by Mechanism 2 of Alkali Cation Transport. Plant Physiol 42:319-323. https://doi.org/10.1104/pp.42.3.319

88. Reimholz R, Geiger M, Haake V et al (1997) Potato plants contain multiple forms of sucrose phosphate synthase, which differ in their tissue distributions, their levels during development, and their responses to low temperature. Plant Cell Environ 20:291-305. https://doi.org/10.1046/j.1365-3040.1997.d01-83.x

89. Ren X-L, Qi G-N, Feng H-Q et al (2013) Calcineurin B-like protein CBL10 directly interacts with AKT1 and modulates K ${ }^{+}$ homeostasis in Arabidopsis. Plant J 74:258-266. https://doi.org/10.1111/tpj.12123

90. Roden LC, Ingle RA (2009) Lights, Rhythms, Infection: The Role of Light and the Circadian Clock in Determining the Outcome of Plant-Pathogen Interactions. Plant Cell 21:2546-2552. https://doi.org/10.1105/tpc.109.069922 
91. Roitsch T (1999) Source-sink regulation by sugar and stress. Curr Opin Plant Biol 2:198-206.

https://doi.org/10.1016/S1369-5266(99)80036-3

92. Roitsch T, Bittner M, Godt DE (1995) Induction of Apoplastic Invertase of Chenopodium rubrum by D-Glucose and a Glucose Analog and Tissue-Specific Expression Suggest a Role in Sink-Source Regulation. Plant Physiol 108:285-294. https://doi.org/10.1104/pp.108.1.285

93. Rolland F, Baena-Gonzalez E, Sheen J (2006) Sugar Sensing and Signalling in Plants: Conserved and Novel Mechanisms. Annu Rev Plant Biol 57:675-709. https://doi.org/10.1146/annurev.arplant.57.032905.105441

94. Rosa M, Hilal M, González JA, Prado FE (2009) Low-temperature effect on enzyme activities involved in sucrose-starch partitioning in salt-stressed and salt-acclimated cotyledons of quinoa (Chenopodium quinoa Willd.) seedlings. Plant Physiol Biochem 47:300-307. https://doi.org/10.1016/j.plaphy.2008.12.001

95. Sarowar S, Lee J-Y, Ahn E-R, Pai H-S (2008) A role of hexokinases in plant resistance to oxidative stress and pathogen infection. J Plant Biol 51:341-346. https://doi.org/10.1007/BF03036136

96. Saxena S, Jónsson ZO, Dutta A (2003) Small RNAs with Imperfect Match to Endogenous mRNA Repress Translation. J Biol Chem 278:44312-44319. https://doi.org/10.1074/jbc.M307089200

97. Schneider CA, Rasband WS, Eliceiri KW (2012) NIH Image to ImageJ: 25 years of image analysis. Nat Methods 9:671-675. https://doi.org/10.1038/nmeth.2089

98. Seifikalhor M, Aliniaeifard S, Shomali A et al (2019) Calcium signaling and salt tolerance are diversely entwined in plants. Plant Signal Behav 14:1665455. https://doi.org/10.1080/15592324.2019.1665455

99. Shishova M, Lindberg S (2004) Auxin induces an increase of Ca2+ concentration in the cytosol of wheat leaf protoplasts. J Plant Physiol 161:937-945. https://doi.org/10.1016/j.jplph.2003.12.005

100. Simonian MH, Smith JA (2001) Spectrophotometric and Colorimetric Determination of Protein Concentration. Current Protocols in Toxicology 10. https://doi.org/10.1002/0471140856.txa03gs10

101. Slama I, Abdelly C, Bouchereau A et al (2015) Diversity, distribution and roles of osmoprotective compounds accumulated in halophytes under abiotic stress. Ann Botany 115:433-447. https://doi.org/10.1093/aob/mcu239

102. Stael S, Wurzinger B, Mair A et al (2012) Plant organellar calcium signalling: an emerging field. J Exp Bot 63:1525-1542. https://doi.org/10.1093/jxb/err394

103. Stitt M, Hurry V (2002) A plant for all seasons: alterations in photosynthetic carbon metabolism during cold acclimation in Arabidopsis. Curr Opin Plant Biol 5:199-206. https://doi.org/10.1016/S1369-5266(02)00258-3

104. Stitt M, Wilke I, Feil R, Heldt HW (1988) Coarse control of sucrose-phosphate synthase in leaves: Alterations of the kinetic properties in response to the rate of photosynthesis and the accumulation of sucrose. Planta 174:217-230. https://doi.org/10.1007/BF00394774

105. Tang R-J, Luan S (2017) Regulation of calcium and magnesium homeostasis in plants: from transporters to signaling network. Curr Opin Plant Biol 39:97-105. https://doi.org/10.1016/j.pbi.2017.06.009

106. Tautz D (1992) Problems and paradigms: Redundancies, development and the flow of information. BioEssays 14:263-266. https://doi.org/10.1002/bies.950140410

107. Tauzin AS, Giardina T (2014) Sucrose and invertases, a part of the plant defense response to the biotic stresses. Front Plant Sci 5. https://doi.org/10.3389/fpls.2014.00293

108. Voß U, Wilson MH, Kenobi K et al (2015) The circadian clock rephases during lateral root organ initiation in Arabidopsis thaliana. Nat Commun 6:7641. https://doi.org/10.1038/ncomms8641

109. Wang Q, Yang S, Wan S, Li X (2019) The Significance of Calcium in Photosynthesis. IJMS 20:1353. https://doi.org/10.3390/ijms20061353

110. Warren CR (2008) Rapid Measurement of Chlorophylls with a Microplate Reader. J Plant Nutr 31:1321-1332. https://doi.org/10.1080/01904160802135092

111. Weber H, Borisjuk L, Wobus U (1997) Sugar import and metabolism during seed development. Trends Plant Sci 2:169-174. https://doi.org/10.1016/S1360-1385(97)85222-3 
112. Xu S, Lai E, Zhao L et al (2020) Development of a fast and efficient root transgenic system for functional genomics and genetic engineering in peach. Sci Rep 10:2836. https://doi.org/10.1038/s41598-020-59626-8

113. Xu W, Cui K, Xu A et al (2015) Drought stress condition increases root to shoot ratio via alteration of carbohydrate partitioning and enzymatic activity in rice seedlings. Acta Physiol Plant 37:9. https://doi.org/10.1007/s11738-014-1760-0

114. Zhu J-K (2002) Salt and drought stress signal transduction in plants. Annu Rev Plant Biol 53:247-273. https://doi.org/10.1146/annurev.arplant.53.091401.143329

\section{Table 1}

Table 1. Primer list for Gateway cloning and RT-qPCR analysis. Asterisk signs indicate the end of attB adapters and the start of gene-specific parts.

\begin{tabular}{|c|c|c|c|}
\hline Gene & Sequence & $\begin{array}{l}\text { Product } \\
\text { length }\end{array}$ & Target \\
\hline \multicolumn{4}{|c|}{ Gateway Cloning } \\
\hline \multirow[t]{2}{*}{ pvSPS4 } & GGGGACAAGTTTGTACAAAAAAGCAGGCTTC*ACCTCTCCCATGTTGAACA & \multirow[t]{2}{*}{280} & \multirow[t]{2}{*}{ Phvul.005G002600 } \\
\hline & GGGGACCACTTTGTACAAGAAAGCTGGGTC*TCAGCAGCAACTACCACA & & \\
\hline \multirow[t]{2}{*}{ human ferritin } & GGGGACAAGTTTGTACAAAAAAGCAGGCTTC*TTACTGCTTTCACCTGCC & \multirow[t]{2}{*}{268} & \multirow[t]{2}{*}{ NC_000011.10 } \\
\hline & GGGGACCACTTTGTACAAGAAAGCTGGGTC*CCAGCGGTGAATGTATGT & & \\
\hline \multicolumn{4}{|l|}{ RT-qPCR } \\
\hline \multirow[t]{2}{*}{ pvSPS4 } & GCAACTTTGGTCGGAGGATG & \multirow[t]{2}{*}{153} & \multirow[t]{2}{*}{ Phvul.005G002600 } \\
\hline & GCTAGAGCACGAGCAAGTTC & & \\
\hline \multirow[t]{2}{*}{ pvSPS1 } & GCTATGGGAGATCCATGCCT & \multirow[t]{2}{*}{172} & \multirow[t]{2}{*}{ Phvul.003G170100 } \\
\hline & CGAGGGTTGGTAAAGAAGCG & & \\
\hline \multirow[t]{2}{*}{ pvSPS3 } & GCATTTCAACCCCACCAAGT & \multirow[t]{2}{*}{194} & \multirow[t]{2}{*}{ Phvul.006G031700 } \\
\hline & TCTGGGTTTCCTCCCATTCC & & \\
\hline \multirow[t]{2}{*}{ Actin-11 } & TGCATACGTTGGTGATGAGG & \multirow[t]{2}{*}{190} & \multirow[t]{2}{*}{ Phvul.008G011000 } \\
\hline & AGCCTTGGGGTTAAGAGGAG & & \\
\hline
\end{tabular}

\section{Tables S1-s3}

Table S1. Anova summary statistics for molecular measurements. 


\begin{tabular}{|c|c|c|c|c|}
\hline & Source of Variation & $\%$ of total variation & $P$ value & $P$ value summary \\
\hline \multirow[t]{3}{*}{$\operatorname{chl} a$} & Interaction & 6.823 & 0.2589 & ns \\
\hline & Knock-down & 16.63 & 0.0468 & * \\
\hline & Salt Treatment & 19.3 & 0.0089 & ** \\
\hline \multirow[t]{3}{*}{$\operatorname{chl} b$} & Interaction & 22.17 & 0.0091 & $\star \star$ \\
\hline & Knock-down & 17.79 & 0.0202 & * \\
\hline & Salt Treatment & 13.74 & 0.0134 & * \\
\hline \multirow[t]{3}{*}{ pvSPS1 ELISA } & Interaction & 0.9328 & 0.7766 & ns \\
\hline & Knock-down & 50.42 & 0.0001 & $\star \star \star$ \\
\hline & Salt Treatment & 4.838 & 0.1166 & ns \\
\hline \multirow[t]{3}{*}{ Glucose } & Interaction & 26.13 & 0.0017 & ** \\
\hline & Knock-down & 14.33 & 0.0204 & * \\
\hline & Salt Treatment & 22.11 & 0.001 & $\star \star \star$ \\
\hline \multirow[t]{3}{*}{ Sucrose } & Interaction & 3.587 & 0.5606 & ns \\
\hline & Knock-down & 11.48 & 0.1716 & ns \\
\hline & Salt Treatment & 12.34 & 0.0547 & ns \\
\hline \multirow[t]{3}{*}{ Glucose/Sucrose } & Interaction & 25.17 & 0.0015 & ** \\
\hline & Knock-down & 7.782 & 0.0889 & ns \\
\hline & Salt Treatment & 32.22 & $<0.0001$ & 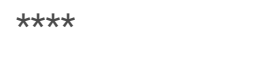 \\
\hline \multirow[t]{3}{*}{ APX } & Interaction & 22.91 & 0.0015 & ** \\
\hline & Knock-down & 15.45 & 0.0089 & $\star \star$ \\
\hline & Salt Treatment & 29.61 & $<0.0001$ & 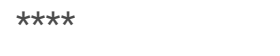 \\
\hline \multirow[t]{3}{*}{ CAT } & Interaction & 18.24 & 0.0169 & * \\
\hline & Knock-down & 22.14 & 0.0082 & $\star \star$ \\
\hline & Salt Treatment & 14.6 & 0.0102 & * \\
\hline \multirow[t]{3}{*}{ Proline - Leaf } & Interaction & 26.83 & $<0.0001$ & 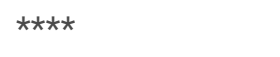 \\
\hline & Knock-down & 12.13 & $<0.0001$ & $\star \star \star \star \star ~$ \\
\hline & Salt Treatment & 55.17 & $<0.0001$ & 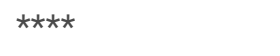 \\
\hline \multirow[t]{3}{*}{ Proline - Root } & Interaction & 13.15 & 0.0004 & 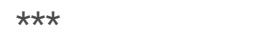 \\
\hline & Knock-down & 44.08 & $<0.0001$ & $\star \star \star \star \star ~$ \\
\hline & Salt Treatment & 28.17 & $<0.0001$ & 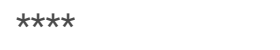 \\
\hline
\end{tabular}

Table S2. Anova summary statistics for physiological measurements. 


\begin{tabular}{|c|c|c|c|c|}
\hline & Source of Variation & $\%$ of total variation & $P$ value & $P$ value summary \\
\hline \multirow[t]{3}{*}{ Leaf Area } & Interaction & 13.93 & 0.0405 & * \\
\hline & Knock-down & 20.18 & 0.0122 & * \\
\hline & Salt Treatment & 20.42 & 0.0031 & $\star \star *$ \\
\hline \multirow[t]{3}{*}{ RWC } & Interaction & 16.83 & 0.0035 & $\star \star$ \\
\hline & Knock-down & 2.416 & 0.3692 & ns \\
\hline & Salt Treatment & 52.85 & $<0.0001$ & 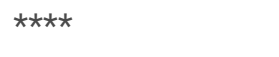 \\
\hline \multirow[t]{3}{*}{$E L-4 h$} & Interaction & 9.188 & 0.0042 & $\star \star$ \\
\hline & Knock-down & 6.954 & 0.0127 & * \\
\hline & Salt Treatment & 68 & $<0.0001$ & $\star \star \star \star ~$ \\
\hline \multirow[t]{3}{*}{ EL - 8h } & Interaction & 3.643 & 0.0651 & ns \\
\hline & Knock-down & 3.841 & 0.057 & ns \\
\hline & Salt Treatment & 78.27 & $<0.0001$ & 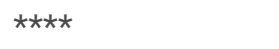 \\
\hline
\end{tabular}

Table S3. Anova summary statistics for ion content measurements. 


\begin{tabular}{|c|c|c|c|c|}
\hline & Source of Variation & $\%$ of total variation & $P$ value & $P$ value summary \\
\hline \multirow[t]{3}{*}{$\mathrm{Na}$ - Leaf } & Interaction & 0.5343 & 0.3741 & ns \\
\hline & Knock-down & 0.5501 & 0.3638 & ns \\
\hline & Salt Treatment & 92.66 & $<0.0001$ & $\star \star \star \star *$ \\
\hline \multirow[t]{3}{*}{$\mathrm{Na}-\mathrm{Root}$} & Interaction & 2.043 & 0.001 & $\star \star$ \\
\hline & Knock-down & 1.387 & 0.0062 & ** \\
\hline & Salt Treatment & 93.94 & $<0.0001$ & $\star \star \star \star \star ~$ \\
\hline \multirow[t]{3}{*}{ K - Leaf } & Interaction & 18.28 & $<0.0001$ & $\star \star \star \star \star ~$ \\
\hline & Knock-down & 3.569 & 0.0129 & * \\
\hline & Salt Treatment & 69.99 & $<0.0001$ & 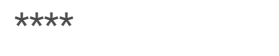 \\
\hline \multirow[t]{3}{*}{ K - Root } & Interaction & 67.01 & $<0.0001$ & 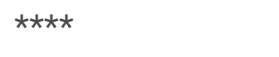 \\
\hline & Knock-down & 3.858 & 0.1784 & ns \\
\hline & Salt Treatment & 4.153 & 0.0572 & ns \\
\hline \multirow[t]{3}{*}{ Ca - Leaf } & Interaction & 48.4 & $<0.0001$ & $\star \star \star \star \star ~$ \\
\hline & Knock-down & 27.24 & $<0.0001$ & 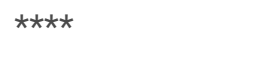 \\
\hline & Salt Treatment & 11.32 & 0.0001 & $\star \star \star$ \\
\hline \multirow[t]{3}{*}{ Ca - Root } & Interaction & 39.9 & 0.0002 & $\star \star \star \star ~$ \\
\hline & Knock-down & 1.833 & 0.5612 & ns \\
\hline & Salt Treatment & 21.1 & 0.0011 & $\star \star$ \\
\hline \multirow[t]{3}{*}{ Mg - Leaf } & Interaction & 61.11 & $<0.0001$ & $\star \star \star * *$ \\
\hline & Knock-down & 2.591 & 0.3615 & ns \\
\hline & Salt Treatment & 7.022 & 0.0246 & * \\
\hline \multirow[t]{3}{*}{$\mathrm{Mg}$ - Root } & Interaction & 14.92 & 0.0477 & * \\
\hline & Knock-down & 33.35 & 0.0026 & ** \\
\hline & Salt Treatment & 0.01178 & 0.9417 & ns \\
\hline
\end{tabular}




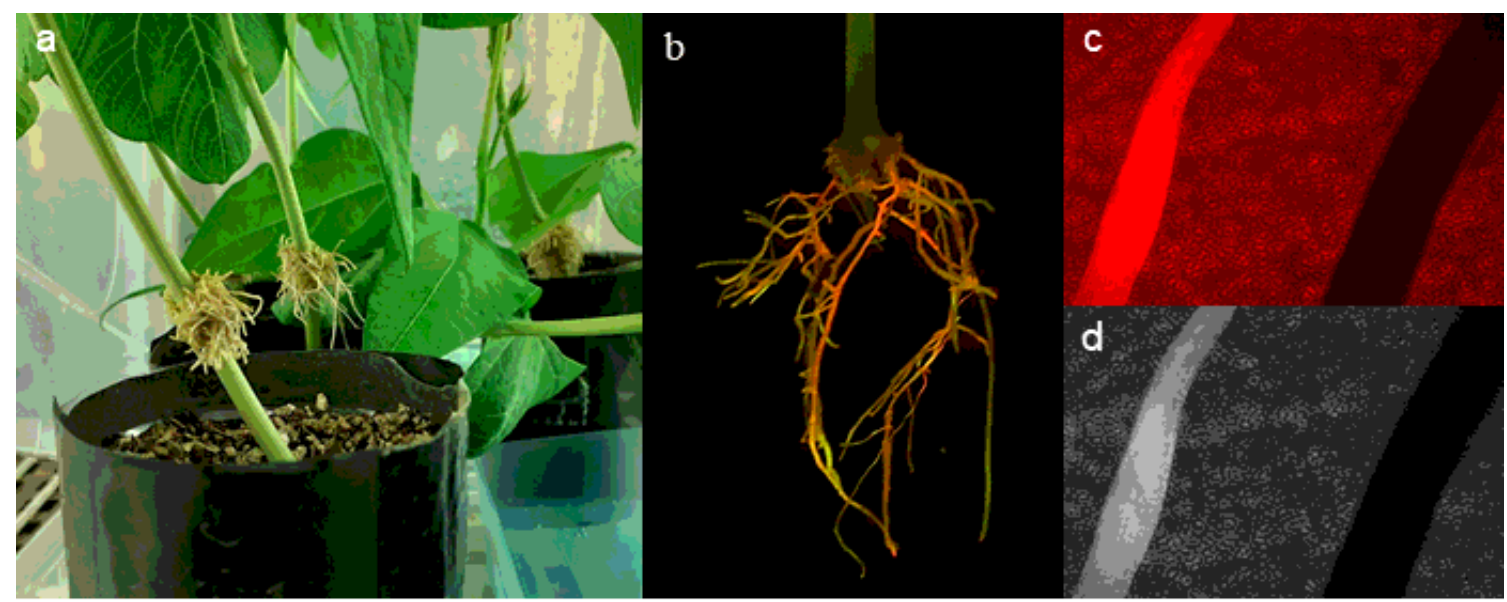

e

\section{Expression of pvSPS4}

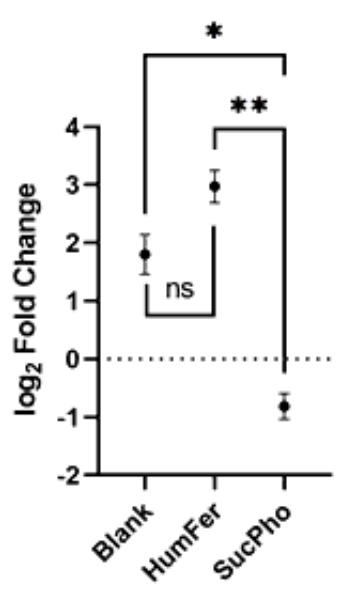

f

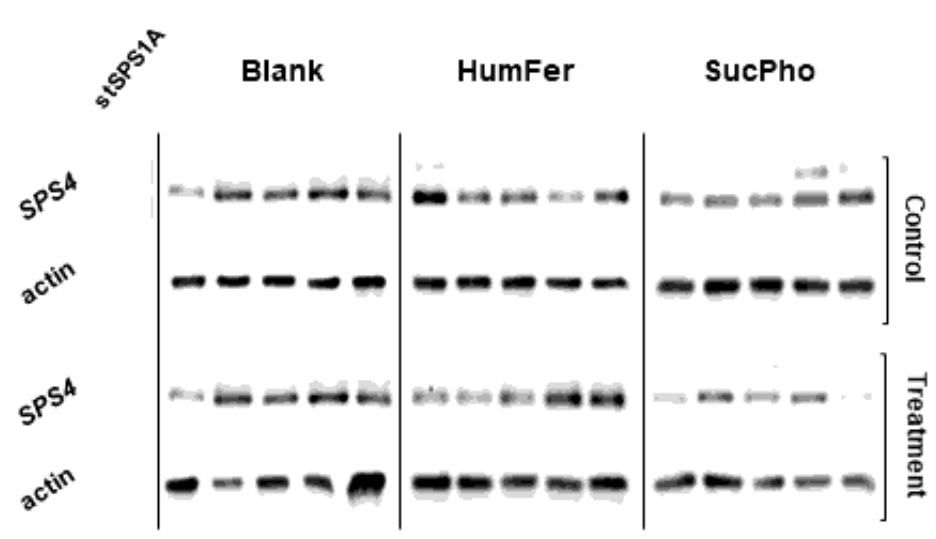

Figure 1

Visualization of hairy root transformation (a-d) and verification of knock down pattern (e-f). Following hairy-root formation (a), genomic insertion was verified with non-destructive photography with orange filter (b). Individual root samples were observed under fluorescence microscope (Axio Observer Z1, ZEISS, DE) (c, d). Knock-down of pvSPS4 under treatment was demonstrated by RT-qPCR $(e)(n=3)$. The amount of pvSPS4 protein decrease was shown by WB $(f)(n=5)$. Values represent the mean \pm SEM 

SPS homologs

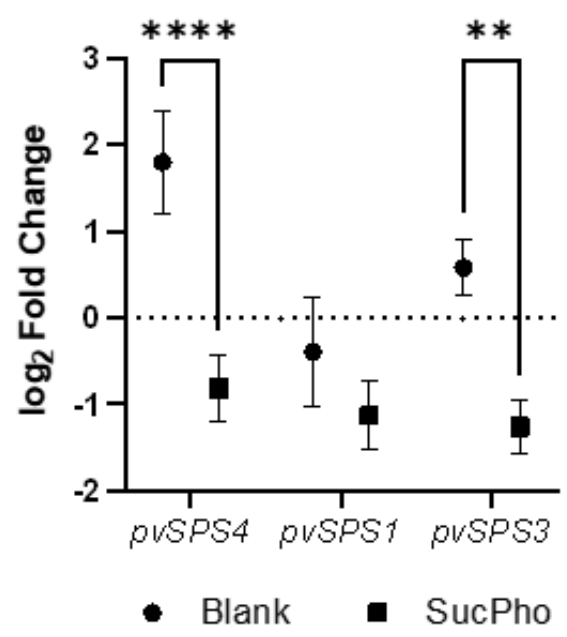

b
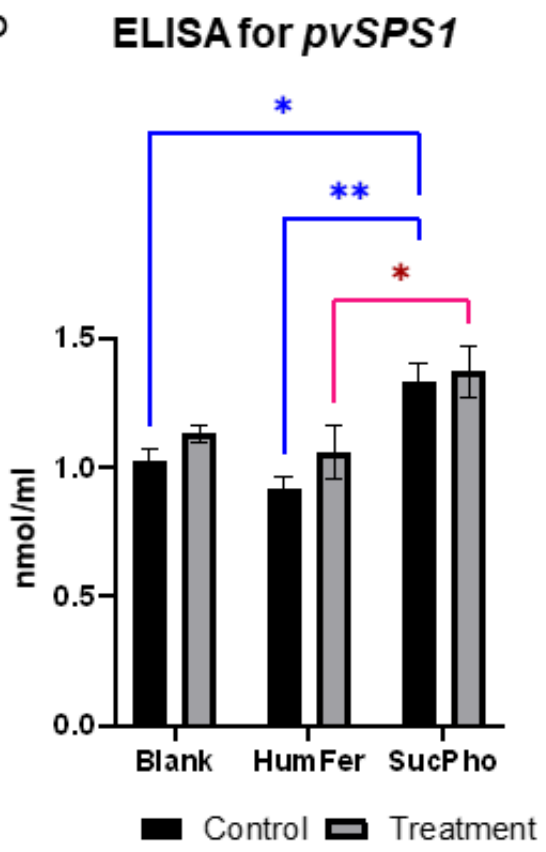

Figure 2

Evaluation of the response of close SPS homologs in root tissues to pvSPS4 knock-down. RT-qPCR of SPS homologs displayed a significant downregulation pattern for $p v S P S 3(a)(n=3)$. Elisa for $p v S P S 1(b)$ demonstrated high protein levels in SucPho plants $(n=5)$. Values represent the mean \pm SEM

a

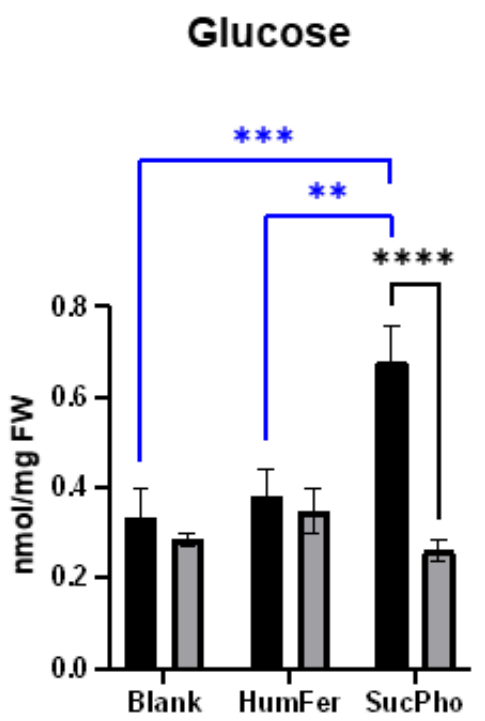

b

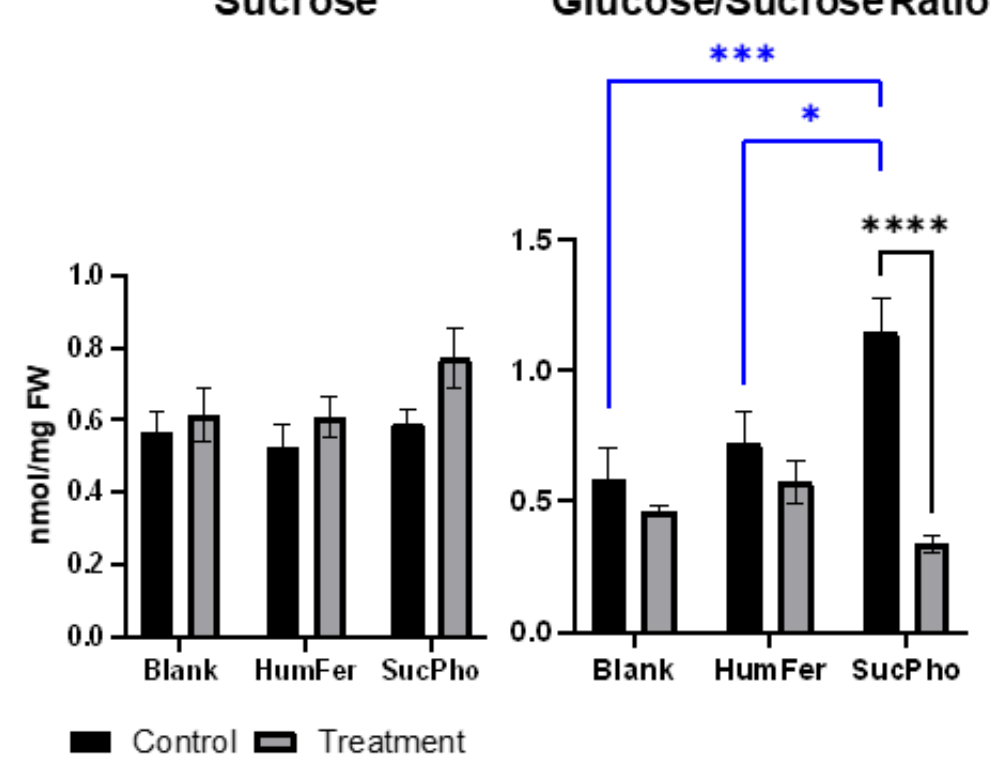

Figure 3

Analysis of glucose and sucrose contents in the root tissues. SucPho roots demonstrated a significant accumulation of glucose in control and decrease in treatment conditions (a). Glucose/sucrose ratios of SucPho roots were significantly different in both control and treatment conditions compared to others $(b)(n=5)$. Values represent the mean \pm SEM 
a

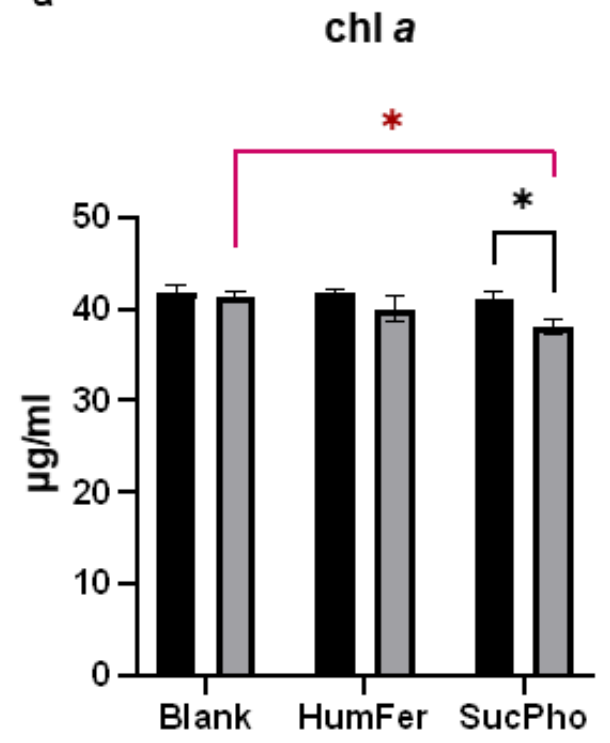

b<smiles>[13CH2]</smiles>

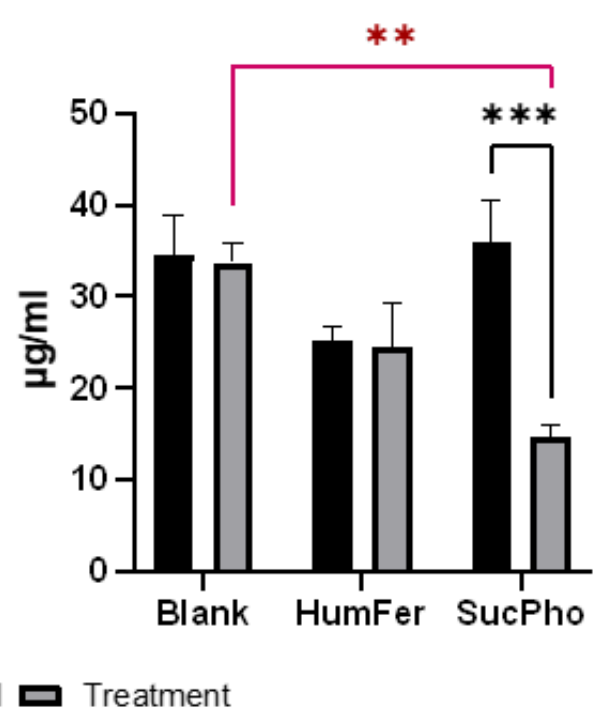

Figure 4

Chlorophyll content analysis of the leaves. SucPho leaves displayed reductions in $c h / a(a)$ and $c h / b$ (b) levels upon salt treatment $(n=5)$. Values represent the mean \pm SEM 
a
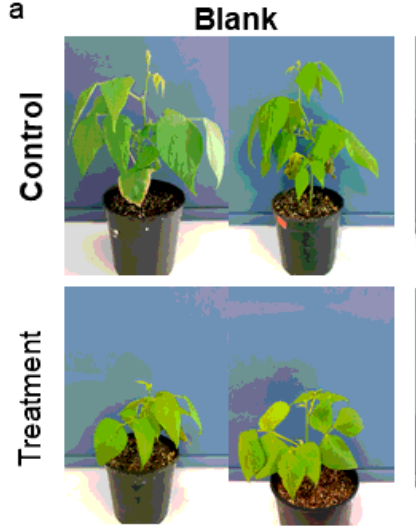

b

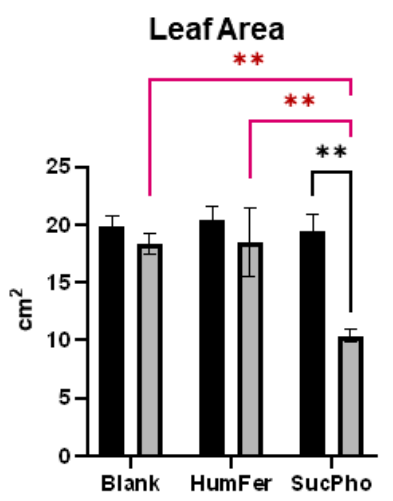

d

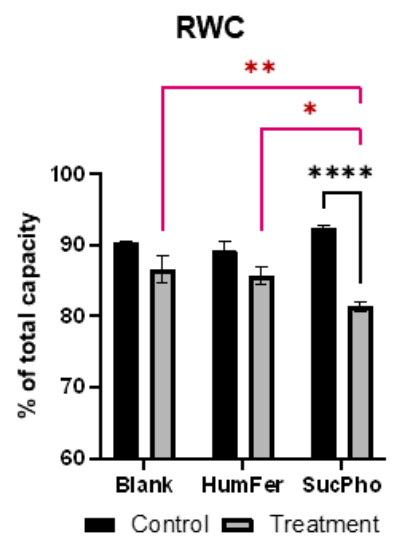

HumFer
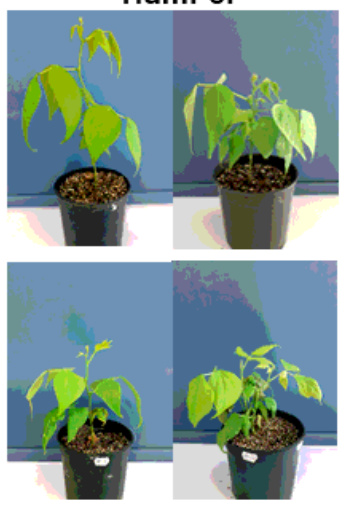

c

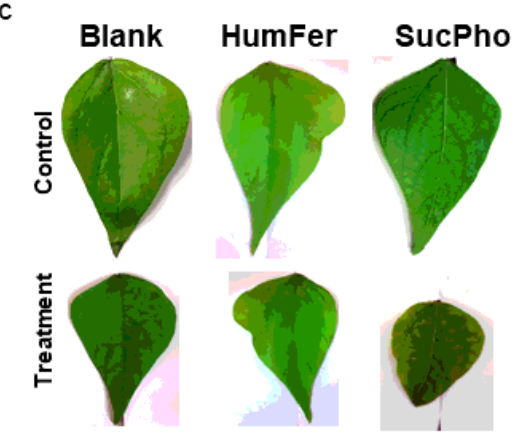

$\Delta \mathrm{EC}$

SucPho
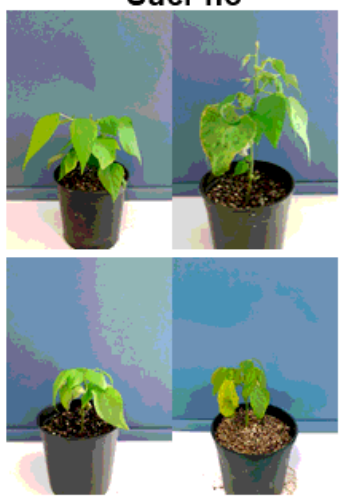

e

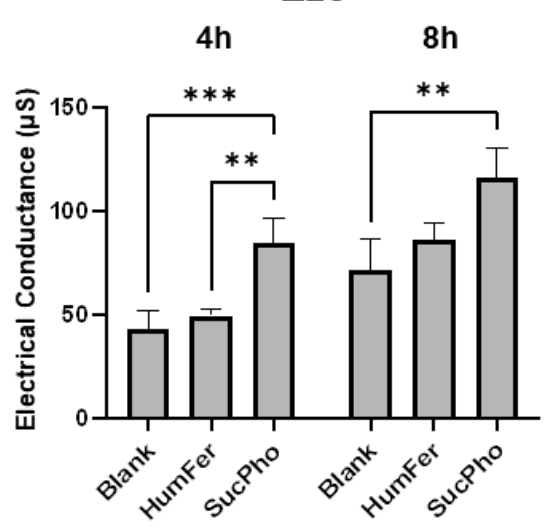

Figure 5

Phenotype and physiological comparisons of composite lines. Blank and HumFer plants displayed similar phenotypes in control and salt-treatment conditions compared to SucPho plants (a). Leaf area measurements (b, c) demonstrated the significant decline in size for SucPho leaves upon salt treatment. SucPho leaves also displayed low RWC (d) and high electrolyte leakage (e) in the treatment conditions $(n=5)$. Values represent the mean \pm SEM 
a

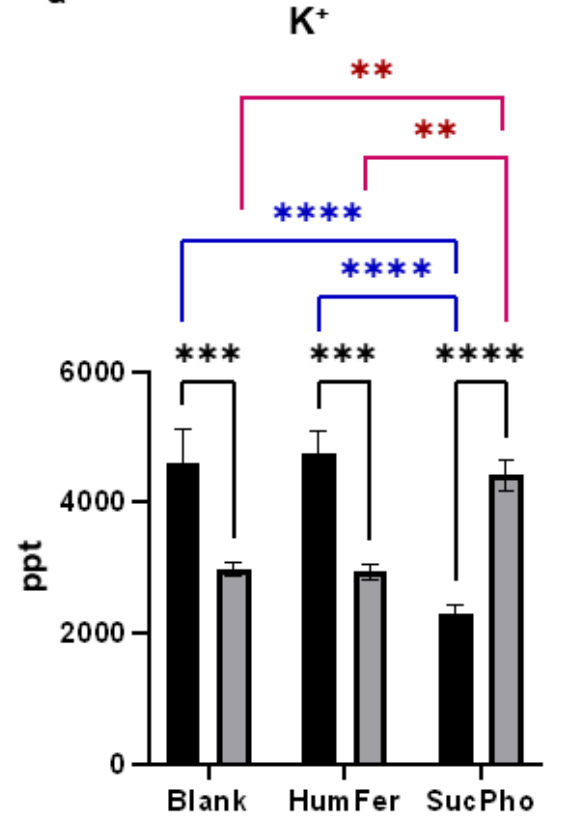

C

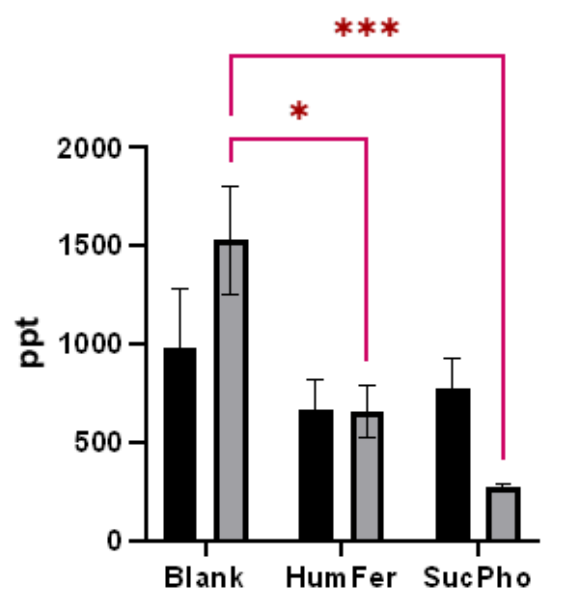

b

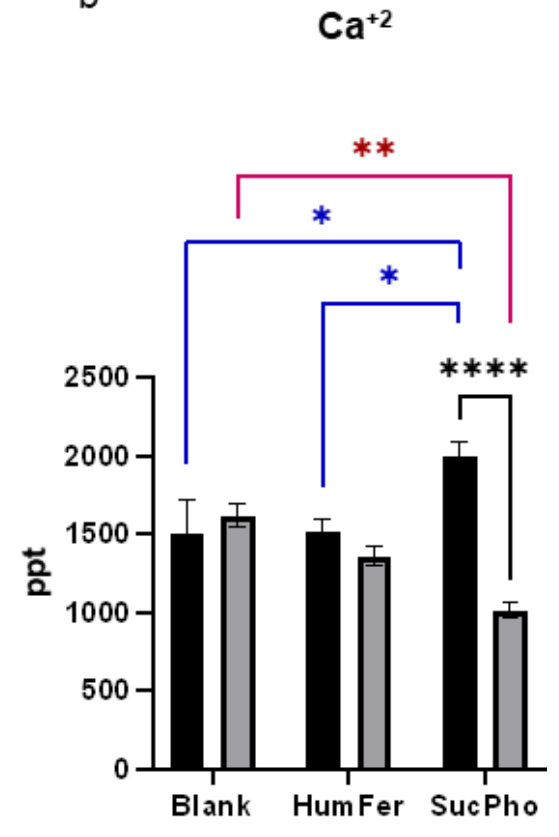

d

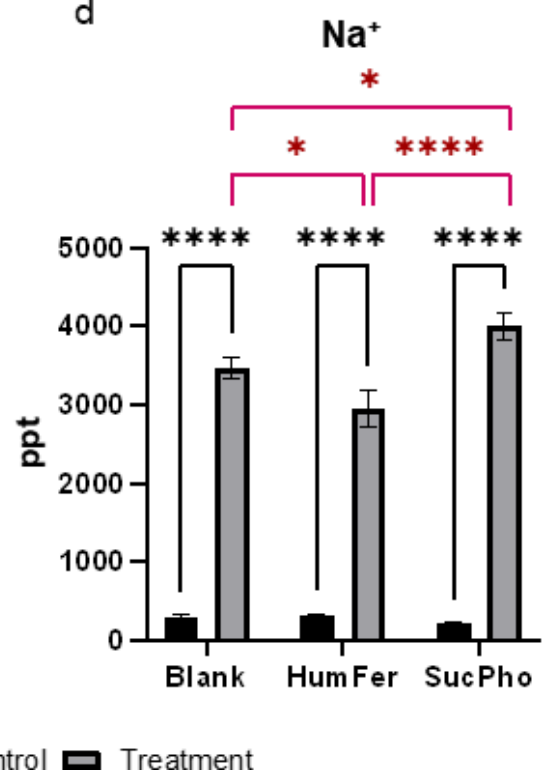

Figure 6

Evaluation of $\mathrm{K}^{+}(\mathrm{a}), \mathrm{Ca}^{+2}(\mathrm{~b}), \mathrm{Mg}^{+2}(\mathrm{c})$, and $\mathrm{Na}^{+}(\mathrm{d})$ content changes in the root tissues of plants. Knock-down of pvSPS4 caused a high disparity in the root systems for the $\mathrm{K}^{+}(\mathrm{a})$ and $\mathrm{Ca}^{+2}$ (b) uptake in control and upon salt-stress conditions. $\mathrm{Mg}^{+2}$ content (c) also displayed a variation between treatment levels. SucPho roots accumulated significantly more $\mathrm{Na}^{+}$in saline conditions (d) ( $\mathrm{n}$ $=5$ ). Values represent the mean \pm SEM. (ppt - parts per thousand) 


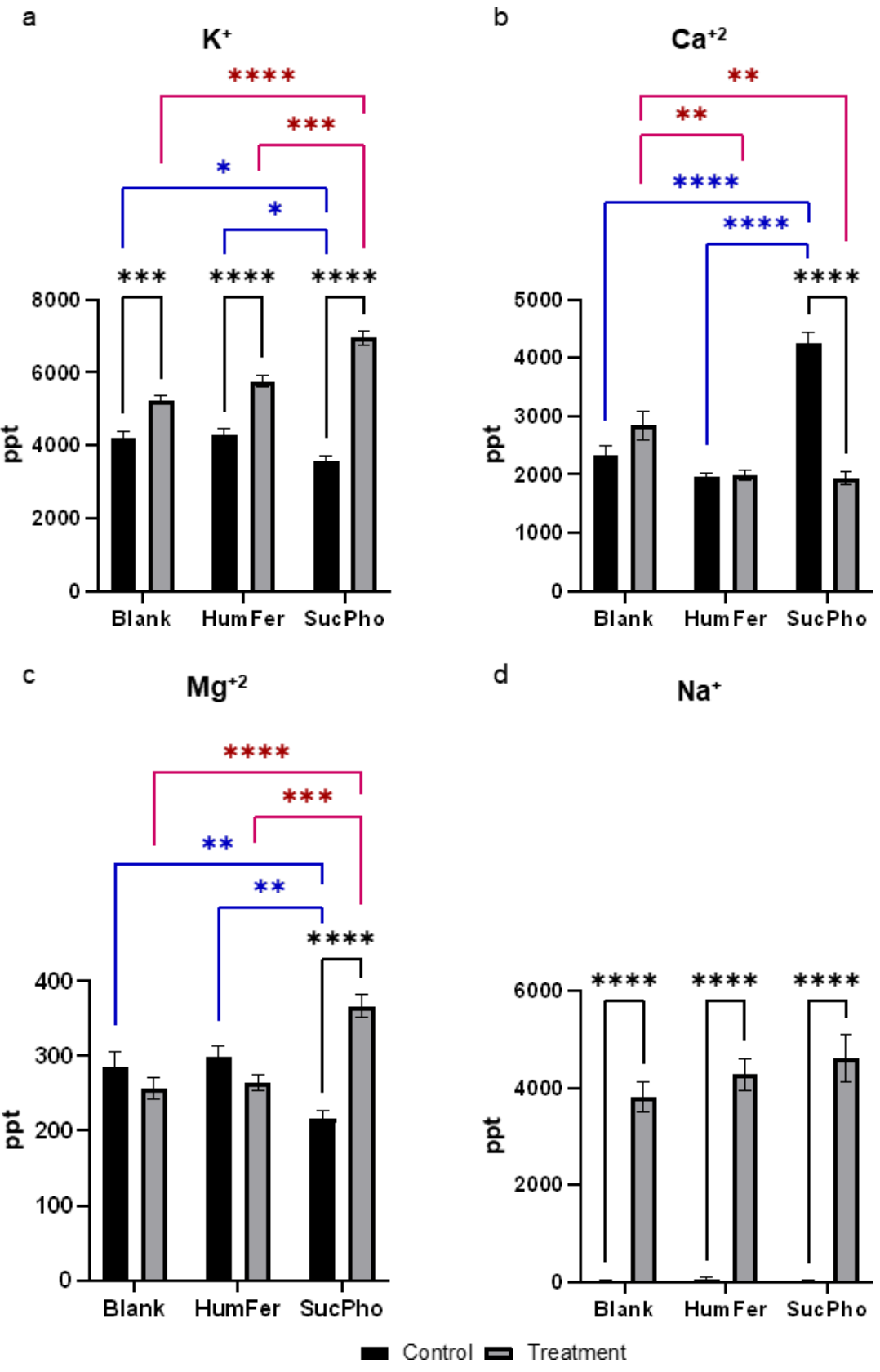

Figure 7

Evaluation of $\mathrm{K}^{+}(\mathrm{a}), \mathrm{Ca}^{+2}(\mathrm{~b}), \mathrm{Mg}^{+2}$ (c), and $\mathrm{Na}^{+}(\mathrm{d})$ content changes in the leaf tissues of plants. All plants accumulated $\mathrm{K}^{+}$ under treatment yet SucPho control and treatment levels were significantly different than others (b). A major imbalance was observed for $\mathrm{Ca}^{+2}$ (b) and $\mathrm{Mg}^{+2}$ contents (c) for SucPho leaves. $\mathrm{Na}^{+}$accumulation did not show a significant difference among plants $(g)(n=5)$. Values represent the mean \pm SEM. (ppt - parts per thousand) 
a Leaf Proline

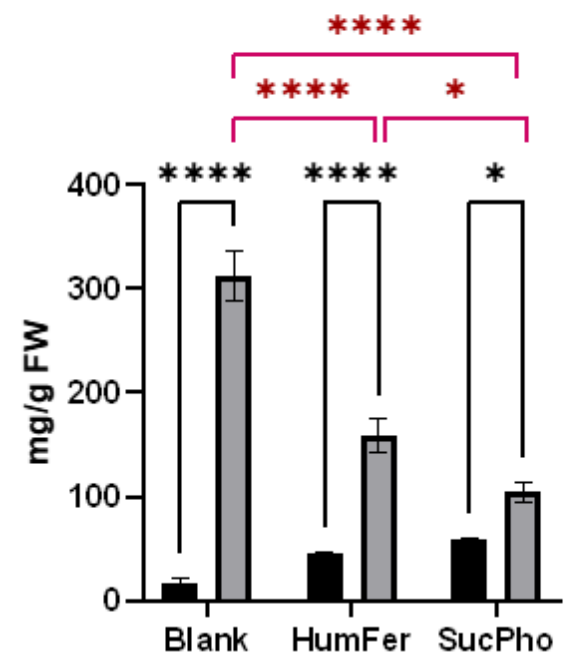

c

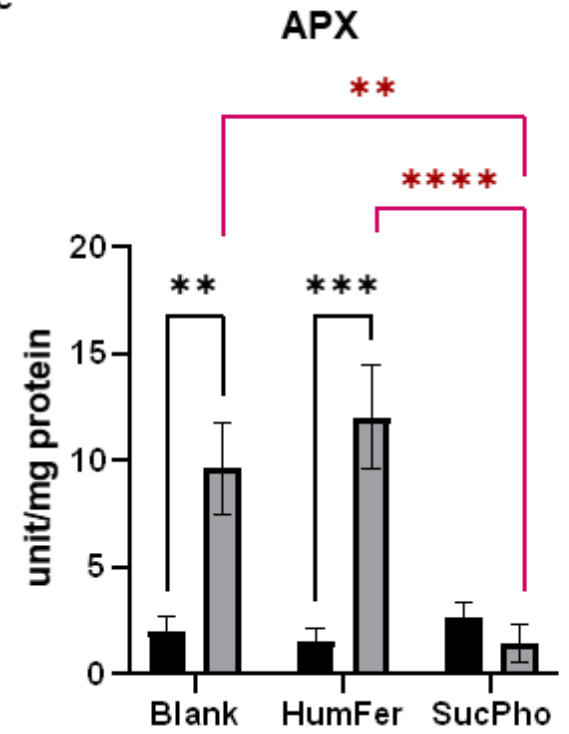

b

\section{Root Proline}

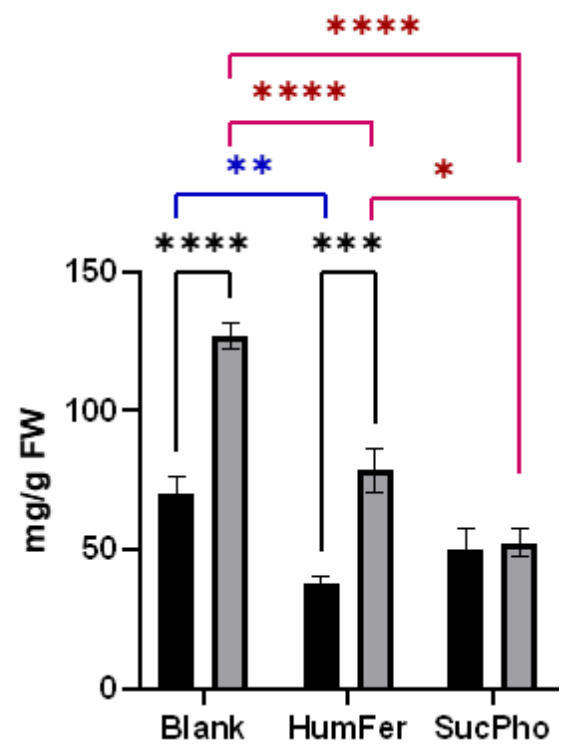

d

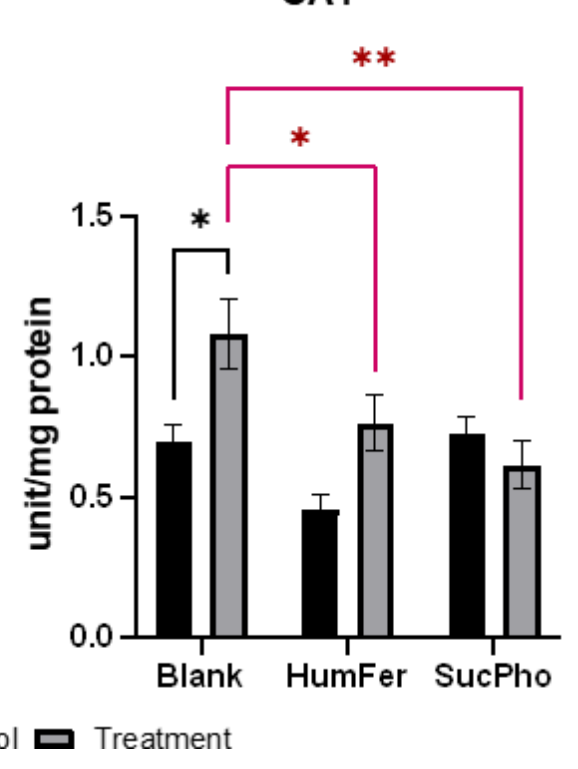

Figure 8

Examination of osmoprotection -proline content ( $a, b)$ - and antioxidant removal -APX (c) and CAT (d) activity - capabilities of plants. All plants accumulated proline in leaves but in significantly different levels (a). In the roots, Blank and HumFer managed to significantly increase its proline content upon salt stress (b). SucPho leaves did not present any escalation in APX (c) or CAT

(d) activity upon treatment, increase in CAT activity was absent in HumFer as well $(n=5)$. Values represent the mean \pm SEM 
a

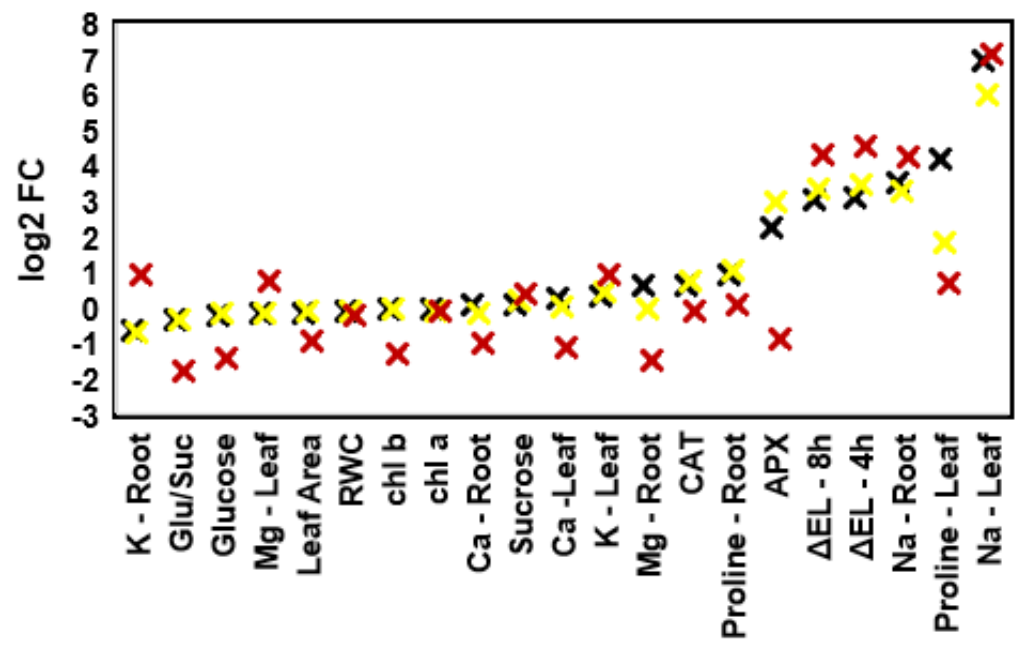

b Correlation for $\log _{2} \mathrm{FC}-r$ values

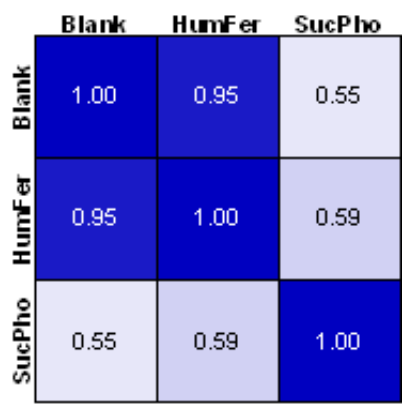

Blank HumFer $\square$ SucPho

Figure 9

Evaluation and comparison of the responses Blank, HumFer, and SucPho gave to salt-stress. Comparison of the $\log _{2}$ foldchanges (a) displayed the disparity of the reactions SucPho (red) gave relative to Blank (black) and HumFer (yellow). Spearman$r$ correlation of $\log _{2}$ fold-changes (b) has shown the distinctions of the plants

\section{Supplementary Files}

This is a list of supplementary files associated with this preprint. Click to download.

- FigS1.tif

- FigS2.tif 